\title{
Can Machine Learning Catch the COVID-19 Recession?
}

PHILIPPE GOULET COULOMBE MASSIMILIANO MARCELLINO DALIBOR STEVANOVIC 


\title{
$\chi \mathrm{CIRANO}$
}

Center for Interuniversity Research and Analysis on Organizations

The purpose of the Working Papers is to disseminate the results of research conducted by CIRANO research members in order to solicit exchanges and comments. These reports are written in the style of scientific publications. The ideas and opinions expressed in these documents are solely those of the authors.

Les cahiers de la série scientifique visent à rendre accessibles les résultats des recherches effectuées par des chercheurs membres du CIRANO afin de susciter échanges et commentaires. Ces cahiers sont rédigés dans le style des publications scientifiques et n'engagent que leurs auteurs.

CIRANO is a private non-profit organization incorporated under the Quebec Companies Act. Its infrastructure and research activities are funded through fees paid by member organizations, an infrastructure grant from the government of Quebec, and grants and research mandates obtained by its research teams.

Le CIRANO est un organisme sans but lucratif constitué en vertu de la Loi des compagnies du Québec. Le financement de son infrastructure et de ses activités de recherche provient des cotisations de ses organisations-membres, d'une subvention d'infrastructure du gouvernement du Québec, de même que des subventions et mandats obtenus par ses équipes de recherche.

\section{CIRANO Partners - Les partenaires du CIRANO}

\section{Corporate Partners - Partenaires corporatifs}

Autorité des marchés financiers

Bank of Canada

Bell Canada

BMO Financial Group

Business Development Bank of Canada

Caisse de dépôt et placement du Québec

Desjardins Group

Énergir

Hydro-Québec

Innovation, Science and Economic Development Canada

Intact Financial Corporation

Manulife Canada

Ministère de l'Économie, de la Science et de l'Innovation

Ministère des finances du Québec

National Bank of Canada

Power Corporation of Canada

PSP Investments

Rio Tinto

Ville de Montréal

\author{
Academic Partners - Partenaires universitaires \\ Concordia University \\ École de technologie supérieure \\ École nationale d'administration publique \\ HEC Montréal \\ McGill University \\ National Institute for Scientific Research \\ Polytechnique Montréal \\ Université de Montréal \\ Université de Sherbrooke \\ Université du Québec \\ Université du Québec à Montréal \\ Université Laval
}

CIRANO collaborates with many centers and university research chairs; list available on its website. Le CIRANO collabore avec de nombreux centres et chaires de recherche universitaires dont on peut consulter la liste sur son site web.

(C) March 2021. Philippe Goulet Coulombe, Massimiliano Marcellino, Dalibor Stevanovic. All rights reserved. Tous droits réservés. Short sections may be quoted without explicit permission, if full credit, including (c) notice, is given to the source. Reproduction partielle permise avec citation du document source, incluant la notice (c)

The observations and viewpoints expressed in this publication are the sole responsibility of the authors; they do not necessarily represent the positions of CIRANO or its partners. Les idées et les opinions émises dans cette publication sont sous l'unique responsabilité des auteurs et ne représentent pas nécessairement les positions du CIRANO ou de ses partenaires. 


\title{
Can Machine Learning Catch the COVID-19 Recession? *
}

\author{
Philippe Goulet Coulombe ${ }^{\dagger}$, Massimiliano Marcellino ${ }^{\ddagger}$, Dalibor Stevanovic $\$$
}

\begin{abstract}
Résumé
Based on evidence gathered from a newly built large macroeconomic data set for the UK, labeled UK-MD and comparable to similar datasets for the US and Canada, it seems the most promising avenue for forecasting during the pandemic is to allow for general forms of nonlinearity by using machine learning (ML) methods. But not all nonlinear ML methods are alike. For instance, some do not allow to extrapolate (like regular trees and forests) and some do (when complemented with linear dynamic components). This and other crucial aspects of ML-based forecasting in unprecedented times are studied in an extensive pseudo-out-of-sample exercise.
\end{abstract}

Keywords/Mots-clés: Machine Learning, Big Data, Forecasting, COVID-19

JEL Codes/Codes JEL: C53, C55, E37

\footnotetext{
* We thank the Editor Ana Galvao, an anonymous referee, and Hugo Couture who provided excellent research assistance. The third author acknowledges financial support from the Chaire en macroéconomie et prévisions ESG UQAM.

${ }^{\dagger}$ University of Pennsylvania

* Bocconi University, IGIER, Baffi-Carefin, BIDSA and CEPR

$\S$ Université du Québec à Montréal and CIRANO
} 


\section{Introduction}

Forecasting economic developments during crisis time is problematic since the realizations of the variables are far away from their average values, while econometric models are typically better at explaining and predicting values close to the average, particularly so in the case of linear models. The situation is even worse for the Covid-19 induced recession, when typically well performing econometric models such as Bayesian VARs with stochastic volatility have troubles in tracking the unprecedented fall in real activity and labour market indicators - see for example for the US Carriero et al. (2020) and Plagborg-Møller et al. (2020), or An and Loungani (2020) for an analysis of the past performance of the Consensus Forecasts.

As a partial solution, Foroni et al. (2020) employ simple mixed-frequency models to nowcast and forecast US and the rest of G7 GDP quarterly growth rates, using common monthly indicators, such as industrial production, surveys, and the slope of the yield curve. They then adjust the forecasts by a specific form of intercept correction or estimate by the similarity approach, see Clements and Hendry (1999) and Dendramis et al. (2020), showing that the former can reduce the extent of the forecast error during the Covid-19 period. Schorfheide and Song (2020) do not include COVID periods in the estimation of a mixed-frequency VAR model because those observations substantially alter the forecasts. An alternative approach is the specification of sophisticated nonlinear / time-varying models. While this is not without perils when used on short economic time series, it can yield some gains, see e.g. Ferrara et al. (2015) in the context of forecasting during the financial crisis using Markov-Switching, threshold and other types of random parameter models.

The goal of this paper is to go one step further in terms of model sophistication, by considering a variety of machine learning (ML) methods and assessing whether and to what extent they can improve the forecasts, both in general and specifically during the Covid-19 crisis, focusing on the UK economy that at the same time was also experiencing substantial Brexit-related uncertainty. A related paper, but with a focus on the largest euro area countries, is Huber et al. (2020) who introduce Bayesian Additive Regression Tree-VARs (BART-VARs) for Covid. They develop a nonlinear mixed-frequency VAR framework by incorporating regression trees, and exploiting their ability to model outliers and to disentangle the signal from noise. Indeed, the regression trees (and even more the forests) are able to quickly adapt to extreme observations and to disentangle the switch in the underlying regime. Another relevant related paper is Goulet Coulombe et al. (2019), which however does not include an analysis of the Covid-19 period and focuses on the US. A third related paper, again with a focus on the US, is Clark et al. (2021), who consider alternative specifications of BART-VARs, possibly with also a non-parametric specification for the time-varying volatility, and compare their point, density and tail forecast performance with that of large Bayesian VARs with stochastic volatility, finding often gains, though of limited size.

In line with Goulet Coulombe et al. (2019), we consider five nonlinear nonparametric ML methods. Three of them have the capacity to extrapolate and two do not. Specifically, being based on trees, boosted trees (BT) and random forests (RF) cannot predict out-of-sample a value $\left(\hat{y}_{i}\right)$ greater 
than the maximal in-sample value (same goes for the minimum). This is a simple implication of how forecasts are constructed, basically by taking means over sub-samples chosen in a data-driven way. Clearly, this is an important limitation when it comes to forecasting variables which significantly got out of their typical range during the Pandemic (like hours worked). ${ }^{1}$ No such constraints bind on Macroeconomic Random Forest (MRF), Kernel Ridge Regression (KRR), and Neural Networks (NN). By using a linear part within the leafs, MRF can extrapolate the same way a linear model does, while retaining the usual benefits of tree-based methods (limited or inexistent overfitting, necessitate little to no tuning, can cope with large data). Goulet Coulombe (2020a) notes that this particular feature gives MRF an edge over RF when it comes to forecasting the (once) extreme escalation of the unemployment rate during the Great Recession.

As mentioned, we focus on the UK and, as another contribution of the paper, we construct a monthly large-scale macroeconomic database, labeled UK-MD, comparable to those for the US by McCracken and $\operatorname{Ng}(2016,2020)$ and for Canada by Fortin-Gagnon et al. (2018). ${ }^{2}$ Specifically, the dataset contains 112 monthly macroeconomic and financial indicators divided into nine categories: labour, production, retail and services, consumer and retail price indices, producer price indices, international trade, money, credit and interest rate, stock market and finally sentiment and leading indicators. The starting date varies across indicators, from 1960 to 2000, and to simplify econometric analyses we also balance the resulting panel using an EM algorithm to impute missing values, as in Stock and Watson (2002b) and McCracken and Ng (2016).

In terms of empirical results, overall ML methods can provide substantial gains when shortterm forecasting several indicators of the UK economy, though a careful temporal and variable by variable analysis is needed. Over the full sample, RF works particularly well for labour market variables, in particular when augmented with a Moving Average Rotation of $X$ ( $X$ being the predictors, hence "MARX"); KRR for real activity and consumer price inflation; LASSO or LASSO+MARX for the retail price index and its version focusing on housing; and RF for credit variables. The gains can be sizable, even $40-50 \%$ with respect to the benchmark, and ML methods were particularly useful during the Covid-19 period. Focusing on the Covid sample, it is clear that nonlinear methods with the ability to extrapolate become extremely competitive. And this goes both ways. For instance, certain MRFs, unlike linear methods or simpler nonlinear ML techniques, procure important improvements by predicting unprecedented values (for hours worked), and avoiding immaterial cataclysms (employment and housing prices).

The rest of the paper is structured as follows. Section 2 introduces the machine learning forecasting framework. Section 3 discusses the forecasting models. Section 4 presents the UK-MD dataset and studies its main features. Section 5 discusses the set-up of the forecasting exercise. Section 6 presents and discusses the results. Section 7 summarizes the key findings and concludes. Additional details and results are presented in Appendices.

\footnotetext{
${ }^{1}$ On the other hand, this could be seen as a foolproof preventing the model to predict incredible values.

${ }^{2}$ The dataset can be found here: http://www.stevanovic.uqam.ca/DS_UKMD.html
} 


\section{Machine Learning Forecasting Framework}

Machine learning algorithms offer ways to approximate unknown and potentially complicated functional forms with the objective of minimizing the expected loss of a forecast over $h$ periods. The focus of the current paper is to construct a feature matrix susceptible to improve the macroeconomic forecasting performance of off-the-shelf ML algorithms. Let $H_{t}=\left[H_{1 t}, \ldots, H_{K t}\right]$ for $t=1, \ldots, T$ be the vector of variables found in a large macroeconomic dataset, such as the FREDMD database of McCracken and $\mathrm{Ng}$ (2016) or the UK-MD dataset described in the next section, and let $y_{t+h}$ be our target variable. We follow Stock and Watson $(2002 a, b)$ and target average growth rates or average differences over $h$ periods ahead

$$
y_{t+h}=g\left(f_{Z}\left(H_{t}\right)\right)+e_{t+h} .
$$

To illustrate this point, define $Z_{t} \equiv f_{Z}\left(H_{t}\right)$ as the $N_{Z}$-dimensional feature vector, formed by combining several transformations of the variables in $H_{t}{ }^{3}$ The function $f_{Z}$ represents the data preprocessing and/or featuring engineering whose effects on forecasting performance we seek to investigate. The training problem for the case of no data pre-processing $\left(f_{Z}=I()\right)$ is

$$
\min _{g \in \mathcal{G}}\left\{\sum_{t=1}^{T}\left(y_{t+h}-g\left(H_{t}\right)\right)^{2}+\operatorname{pen}(g ; \tau)\right\}
$$

The function $g$, chosen as a point in the functional space $\mathcal{G}$, maps transformed inputs into the transformed targets. pen () is the regularization function whose strength depends on some vector/scalar hyperparameter(s) $\tau$.

\section{Forecasting Models}

In this section we present the main predictive models (for a more complete discussion, see, among other, Hastie et al. (2009)), and some additional, less standard, forecasting models we will consider (more details can be found in Goulet Coulombe et al. (2019)). Table 1 lists all the models implemented in the forecasting exercise, together with their respective input matrices $Z_{t}$.

\subsection{Main models}

LineAR Models. We consider the autoregressive model (AR), as well as the autoregressive diffusion index (ARDI) model of Stock and Watson $(2002 \mathrm{a}, \mathrm{b})$. Let $Z_{t}=\left[y_{t}, y_{t-1} \ldots, y_{t-P_{y}}, F_{t}, F_{t-1} \ldots, F_{t-P_{f}}\right]$ be our feature matrix, then the ARDI model is given by

$$
\begin{aligned}
y_{t+h} & =\beta Z_{t}+\epsilon_{t+h} \\
X_{t} & =\Lambda F_{t}+u_{t}
\end{aligned}
$$

${ }^{3}$ Obviously, in the context of a pseudo-out-of-sample experiment, feature matrices must be built recursively to avoid data snooping. 
where $F_{t}$ are $k$ factors extracted by principal components from the $N_{X}$-dimensional set of predictors $X_{t}$ and parameters are estimated by OLS. The AR model is obtained by keeping in $Z_{t}$ only the lagged values of $y_{t}$. The hyperparameters of both models are specified using the Bayesian information criterion (BIC).

Ridge, Lasso, and Elastic Net. The Elastic Net model simultaneously predicts the target variable $y_{t+h}$ and selects the most relevant predictors from a set of $N_{Z}$ features contained in $Z_{t}$ whose weights $\beta:=\left(\beta_{i}\right)_{i=1}^{N_{Z}}$ solve the following penalized regression problem

$$
\hat{\beta}:=\underset{\beta}{\operatorname{argmin}} \sum_{t=1}^{T}\left(y_{t+h}-Z_{t} \beta\right)^{2}+\lambda \sum_{i=1}^{N_{Z}}\left(\alpha\left|\beta_{i}\right|+(1-\alpha) \beta_{i}^{2}\right)
$$

and where $(\alpha, \lambda)$ are hyperparameters. Here, $Z_{t}$ contains lagged values of $y_{t}$, factors and $X_{t}$. The Lasso estimator is obtained when $\alpha=1$, while the Ridge estimator imposes $\alpha=0$ and both use unit weights throughout. We select $\lambda$ and $\alpha$ with grid search where $\alpha \in\{.01, .02, .03, \ldots, 1\}$ and $\lambda \in\left[0, \lambda_{\max }\right]$ where $\lambda_{\max }$ is the penalty term beyond which coefficients are guaranteed to be all zero assuming $\alpha \neq 0$. Since those algorithms performs shrinkage (and selection), we do not crossvalidate $P_{y}, P_{f}$ and $k$. We impose $P_{y}=6, P_{f}=6$ and $k=8$ and let the algorithms select the most relevant features for forecasting task at hand.

RANDOM FORESTS. This algorithm provides a means of approximating nonlinear functions by combining regression trees. Each regression tree partitions the feature space defined by $Z_{t}$ into distinct regions and, in its simplest form, uses the region-specific mean of the target variable $y_{t+h}$ as the forecast, i.e. for $M$ leaf nodes

$$
\hat{y}_{t+h}=\sum_{m=1}^{M} c_{m} I_{\left(Z_{t} \in R_{m}\right)}
$$

where $R_{1}, \ldots, R_{M}$ is a partition of the feature space. The input $Z_{t}$ is the same as in the case of Elastic Net models. To circumvent some of the limitations of regression trees, Breiman (2001) introduced Random Forests. Random Forests consist in growing many trees on subsamples (or nonparametric bootstrap samples) of observations. A random subset of features is eligible for the splitting variable, further decorrelating them. The final forecast is obtained by averaging over the forecasts of all trees. In this paper we use 500 trees which is normally enough to stabilize the predictions. The minimum number of observation in each terminal nodes is set to 3 while the number of features considered at each split is $\frac{\# Z_{t}}{3}$. In addition, we impose $P_{y}=6, P_{f}=6$ and $k=8$.

Boosted TREes. This algorithm provides an alternative means of approximating nonlinear functions by additively combining regression trees in a sequential fashion. Let $\eta \in[0,1]$ be the learning rate and $\hat{y}_{t+h}^{(n)}$ and $e_{t+h}^{(n)}:=y_{t-h}-\eta \hat{y}_{t+h}^{(n)}$ be the step $n$ predicted value and pseudo-residuals, respec- 
tively. Then, for square loss, the step $n+1$ prediction is obtained as

$$
\hat{y}_{t+h}^{(n+1)}=y_{t+h}^{(n)}+\rho_{n+1} f\left(Z_{t}, c_{n+1}\right)
$$

where $\left(c_{n+1}, \rho_{n+1}\right):=\underset{\rho, c}{\operatorname{argmin}} \sum_{t=1}^{T}\left(e_{t+h}^{(n)}-\rho_{n+1} f\left(Z_{t}, c_{n+1}\right)\right)^{2}$ and $c_{n+1}:=\left(c_{n+1, m}\right)_{m=1}^{M}$ are the parameters of a regression tree. In other words, it recursively fits trees on pseudo-residuals. We consider a vanilla Boosted Trees where the maximum depth of each tree is set to 10 and all features are considered at each split. We select the number of steps and $\eta \in[0,1]$ with Bayesian optimization. $Z_{t}$ contains lagged values of $y_{t}$, factors and $X_{t}$, and we impose $P_{y}=6, P_{f}=6$ and $k=8$.

KeRnel Ridge Regressions. A way to introduce high-order nonlinearities among predictors' set $Z_{t}$, but without specifying a plethora of basis functions, is to opt for the Kernel trick. As in Goulet Coulombe et al. (2019), the nonlinear ARDI predictive equation (3) is written in a general nonlinear form $g\left(Z_{t}\right)$ and can be approximated with basis functions $\phi()$ such that

$$
y_{t+h}=g\left(Z_{t}\right)+\varepsilon_{t+h}=\phi\left(Z_{t}\right)^{\prime} \gamma+\varepsilon_{t+h}
$$

The so-called Kernel trick is the fact that there exist a reproducing kernel $K()$ such that

$$
\hat{E}\left(y_{t+h} \mid Z_{t}\right)=\sum_{i=1}^{t} \hat{\alpha}_{i}\left\langle\phi\left(Z_{i}\right), \phi\left(Z_{t}\right)\right\rangle=\sum_{i=1}^{t} \hat{\alpha}_{i} K\left(Z_{i}, Z_{t}\right) .
$$

This means we do not need to specify the numerous basis functions, a well-chosen kernel implicitly replicates them. Here we use the standard radial basis function (RBF) kernel

$$
K_{\sigma}\left(\mathbf{x}, \mathbf{x}^{\prime}\right)=\exp \left(-\frac{\left\|\mathbf{x}-\mathbf{x}^{\prime}\right\|^{2}}{2 \sigma^{2}}\right)
$$

where $\sigma$ is a tuning parameter to be chosen by cross-validation. In terms of implementation, after factors are extracted via PCA from (4), the forecast of the Kernel Ridge Regression (KRR) diffusion index model is obtained from

$$
\hat{E}\left(y_{t+h} \mid Z_{t}\right)=K_{\sigma}\left(Z_{t}, Z\right)\left(K_{\sigma}\left(Z_{t}, Z\right)+\lambda I_{T}\right)^{-1} y_{t}
$$

Here, we impose the same set of inputs, $Z_{t}$, as in the ARDI model and we fix $P_{y}=6, P_{f}=6$ and $k=8$.

Neural Networks. We consider standard feed-forward networks and the architecture closely follows that of $\mathrm{Gu}$ et al. (2019). Cross-validating the whole network architecture is a difficult task especially with a small number of observations as is the case in macroeconomic applications. Hence, we use two hidden layers, the first with 32 neurons and the second with 16 neurons. The 
number of epochs is fixed at 100. The activation function is ReLu and that of the output layer is linear. The batch size is 32 and the optimizer is Adam (Keras default values). The learning rate and the Lasso parameter are chosen by 5-fold cross-validation among the following grids respectively, $\in\{0.001,0.01\}$ and $\in\{0.001,0.0001\}$. We apply the early stopping, i.e. we wait for 20 epochs to pass without any improvement of the cross-validation MSE to stop the training. The final prediction is the average of an ensemble of 5 different estimations. $Z_{t}$ contains lagged values of $y_{t}$, factors and $X_{t}$, and we impose $P_{y}=6, P_{f}=6$ and $k=8$.

\subsection{Additional Forecasting Models}

Macroeconomic RAndom Forests. Goulet Coulombe (2020a) proposes a new form of RF better suited for macroeconomic data. The new problem is to extract generalized time-varying parameters (GTVPs)

$$
\begin{aligned}
& y_{t}=\tilde{X}_{t} \beta_{t}+\epsilon_{t} \\
& \beta_{t}=\mathcal{F}\left(S_{t}\right)
\end{aligned}
$$

where $S_{t}$ are the state variables governing time variation and $\mathcal{F}$ a forest. $S_{t}$ is (preferably) a highdimensional macroeconomic data set. In this paper, it is the same $Z_{t}$ as in plain RF and Boosting. $\tilde{X}$ determines the linear model that we want to be time-varying. Usually $\tilde{X} \subset S$ is rather small (and focused) compared to $S$. For instance, an autoregressive random forests (ARRF) uses lags of $y_{t}$ for $\tilde{X}_{t}$. A factor-augmented ARRF (FA-ARRF) adds factors to ARRF's linear part.

The problem is to find the optimal variable $S_{j}$ (so, finding the best $j$ out of the random subset of predictors indexes $\mathcal{J}^{-}$) to split the sample with, and at which value $c$ of that variable should we split. The outputs should be $j^{*}$ and $c^{*}$ to be used to split $l$ (the parent node) into two children nodes, $l_{1}$ and $l_{2}$. Hence, the greedy algorithm developed in Goulet Coulombe (2020a) runs

$$
\begin{aligned}
\min _{j \in \mathcal{J}^{-}, c \in \mathbb{R}}\left[\min _{\beta_{1}} \sum_{t \in l_{1}^{R W}(j, c)} w(t ; \zeta)\left(y_{t}-\tilde{X}_{t} \beta_{1}\right)^{2}+\lambda\left\|\beta_{1}\right\|_{2}\right. \\
\left.+\min _{\beta_{2}} \sum_{t \in l_{2}^{R W}(j, c)} w(t ; \zeta)\left(y_{t}-\tilde{X}_{t} \beta_{2}\right)^{2}+\lambda\left\|\beta_{2}\right\|_{2}\right] .
\end{aligned}
$$

recursively to construct trees.

As it was the case for RF, the bulk of regularization comes from taking the average over a diversified ensemble of trees (generated by both Bagging and a random $\mathcal{J}^{-} \subset \mathcal{J}$. Nonetheless, $\beta_{t}$ 's (and the attached prediction) can also benefit from extra (yet mild) regularization. Time-smoothness is made operational by taking the "rolling-window view" of time-varying parameters. That is, the tree solve many weighted least squares problems (WLS) which includes close-by observations. To keep computational demand low, the kernel $w(t ; \zeta)$ is a symmetric 5-step Olympic podium. Informally, the kernel puts a weight of 1 on observation $t$, a weight of $\zeta<1$ for observations $t-1$ and 
$t+1$ and a weight of $\zeta^{2}$ for observations $t-2$ and $t+2$. Note that a small Ridge penalty is added to make sure every matrix inverts nicely (even in very small leaves), so a single tree has in fact two sources of regularization.

The standard RF is a restricted version of MRF where $\tilde{X}_{t}=\iota, \lambda=0, \zeta=0$ and the block size for Bagging is 1. In words, the only regressor is a constant, there is no within-leaf shrinkage, and Bagging does not care for serial dependence. It is understood that MRF will have an edge over $R F$ whenever linear signals included in $\tilde{X}_{t}$ are strong and the number of training observations (or signal-to-noise ratio) is low. The reason for this is simple: MRF nudge the learning algorithm in the right direction rather than hoping for RF to learn everything non-parametrically. Moreover, by providing generalized time-varying parameters (and credible regions for those), MRF lends itself more easily to interpretation.

Moving Average Rotation of X. The Moving Average Rotation of X (MARX) transformation was proposed in Goulet Coulombe et al. (2020) as a feature engineering technique which generates an implicit shrinkage more appropriate for time series data. In linear setup when coefficients are shrunk (and maybe selected) to 0, using MARX transform the usual $\beta_{k, p} \rightarrow 0$ prior into shrinking each $\beta_{k, p}$ to $\beta_{k, p-1}$ for the $p$ lag of predictor $k$. For more sophisticated techniques where shrinkage is only implicit (like RF and Boosting), MARX "proposes" the variable-selecting algorithm with pre-assembled group of lags which helps in avoiding that the underlying trees waste splits on a bunch of scattered lags (Goulet Coulombe, 2020a). Goulet Coulombe et al. (2020) report that the transformation is particularly helpful for US monthly real economic activity targets. Adding MARX to the input set $Z_{t}$ is considered in all models except ARDI and KRR.

\section{UK-MD: A Large UK Monthly Macroeconomic Data Set}

Large datasets are now very popular in empirical macroeconomic research since Stock and Watson $(2002 a, b)$ have initiated the breakthrough by providing the econometric theory and showing the benefits in terms of macroeconomic forecasting. McCracken and $\operatorname{Ng}(2016,2020)$ proposed a standardized version of a large monthly and quarterly US datasets that are regularly updated and publicly available at the FRED (Federal Reserve Economic Data) website. Fortin-Gagnon et al. (2018) have developed the Canadian version of FRED. In this paper, we construct a similar largescale UK macroeconomic database in monthly frequency that can be used in the same way as the US and the Canadian data sets. The dataset is described in the first subsection and analyzed in the second one.

\subsection{UK-MD}

The dataset contains 112 macroeconomic and financial indicators divided into nine categories: labour, production, retail and services, consumer and retail price indices, producer price indices, international trade, money, credit and interest rate, stock market and finally sentiment and leading indicators. The selection of variables is inspired by McCracken and Ng (2016), Fortin-Gagnon et al. 
Table 1: Forecasting Models

\begin{tabular}{|c|c|c|}
\hline Name & Acronym & Input $\left(Z_{t}\right)$ \\
\hline Autoregression (with $P_{y}$ chosen by BIC) & AR,BIC & {$\left[y_{t-\{1: 6\}}\right]$} \\
\hline Random Walk & RW & $\varnothing$ \\
\hline Factor-Augmented AR (with $P_{y}, M_{k}$ and $K$ chosen by BIC) & ARDI,BIC & {$\left[y_{t-\{1: 6\}}, F_{1: 8, t-\{1: 6\}}\right]$} \\
\hline LASSO & LASSO & {$\left[y_{t-\{1: 6\}}, F_{1: 8, t-\{1: 6\}}, X\right]$} \\
\hline LASSO using MARX & LASSO+MARX & {$\left[y_{t-\{1: 6\}}, F_{1: 8, t-\{1: 6\}}, X, M A R X\right]$} \\
\hline Ridge & RIDGE & {$\left[y_{t-\{1: 6\}}, F_{1: 8, t-\{1: 6\}}, X\right]$} \\
\hline Ridge using MARX & RIDGE+MARX & {$\left[y_{t-\{1: 6\}}, F_{1: 8, t-\{1: 6\}}, X, M A R X\right]$} \\
\hline Elastic-Net & E-NET & {$\left[y_{t-\{1: 6\}}, F_{1: 8, t-\{1: 6\}}, X\right]$} \\
\hline Elastic-Net using MARX & E-NET+MARX & {$\left[y_{t-\{1: 6\}}, F_{1: 8, t-\{1: 6\}}, X, M A R X\right]$} \\
\hline Kernel Ridge Regression & KRR & {$\left[y_{t-\{1: 6\}}, F_{1: 8, t-\{1: 6\}}\right]$} \\
\hline Random Forest & $\mathbf{R F}$ & {$\left[y_{t-\{1: 6\}}, F_{1: 8, t-\{1: 6\}}, X\right]$} \\
\hline Random Forest using MARX & RF+MARX & {$\left[y_{t-\{1: 6\}}, F_{1: 8, t-\{1: 6\}}, X, M A R X\right]$} \\
\hline Boosting & Boosting & {$\left[y_{t-\{1: 6\}}, F_{1: 8, t-\{1: 6\}}, X\right]$} \\
\hline Boosting using MARX & Boosting+MARX & {$\left[y_{t-\{1: 6\}}, F_{1: 8, t-\{1: 6\}}, X, M A R X\right]$} \\
\hline AR Random Forest (linear part is $\left[y_{t-\{1: 2\}}\right]$ ) & $\operatorname{ARRF}(2)$ & {$\left[y_{t-\{1: 6\}}, F_{1: 8, t-\{1: 6\}}, X, M A R X\right]$} \\
\hline AR Random Forest (linear part is $\left.\left[y_{t-\{1: 6\}}\right]\right)$ & ARRF(6) & {$\left[y_{t-\{1: 6\}}, F_{1: 8, t-\{1: 6\}}, X, M A R X\right]$} \\
\hline Factor-Augmented AR RF (linear part is $\left[y_{t-\{1: 2\}}, F_{1: 2, t-1}\right]$ ) & FA-ARRF(2,2) & {$\left[y_{t-\{1: 6\}}, F_{1: 8, t-\{1: 6\}}, X, M A R X\right]$} \\
\hline Factor-Augmented AR RF (linear part is $\left[y_{t-\{1: 2\}}, F_{1: 4, t-1}\right]$ ) & FA-ARRF $(2,4)$ & {$\left[y_{t-\{1: 6\}}, F_{1: 8, t-\{1: 6\}}, X, M A R X\right]$} \\
\hline Neural Network & NN-ARDI & {$\left[y_{t-\{1: 6\}}, F_{1: 8, t-\{1: 6\}}, X\right]$} \\
\hline Neural Network using MARX & NN-ARDI+MARX & {$\left[y_{t-\{1: 6\}}, F_{1: 8, t-\{1: 6\}}, X, M A R X\right]$} \\
\hline
\end{tabular}

(2018) and Joseph et al. (2021). The complete list of series is available in the data appendix C. Most of the indicators are available at the Office of National Statistics, while others are taken from the Bank of England, FRED and Yahoo finance. The starting date varies across indicators, from 1960 to 2000. For the forecasting application in this paper, data start in 1998M01.

Most of the series included in the database must be transformed to induce stationarity. We roughly follow McCracken and Ng (2016) and Fortin-Gagnon et al. (2018). For instance, most I(1) series are transformed in the first difference of logarithms; a first difference of levels is applied to unemployment rate and interest rates; and the first difference of logarithms is used for all price indices. Transformation codes are reported in data appendix.

Our last concern is to balance the resulting panel since some series have missing observations. We opted to apply an expectation-maximization algorithm by assuming a factor model to fill in the blanks as in Stock and Watson (2002b) and McCracken and Ng (2016). We initialize the algorithm by replacing missing observations with their unconditional mean, starting in 1998M1, and then proceed to estimate a factor model by principal component. The fitted values of this model are used to replace missing observations. 
Finally, for this application we also add nineteen US macroeconomic and financial aggregates as considered in Banbura et al. (2008). These series include income, production, labour market, housing, consumption and monetary indicators, as well as interest rates and prices. The complete list is available in the appendix D.

\subsection{Exploring the Factor Structure of UK-MD}

Large macroeconomic datasets are mainly used for forecasting and impulse response analysis through lenses of factor modeling (Kotchoni et al., 2019; Bernanke et al., 2005). Indeed, the factors provide a widely used dimension reduction method, but they also serve as an empirical representation of general equilibrium models (Boivin and Giannoni, 2006). Hence, it is important to explore the factor structure of our UK-MD dataset.

Estimating the number of factors is an empirical challenge and several statistical decision procedures have been proposed, see Mao Takongmo and Stevanovic (2015) for review. Here, we select the number of static factors using the Bai and $\mathrm{Ng}$ (2002) $P C_{p 2}$ criterion, and we follow Hallin and Liska (2007) to test for the number of dynamic factors. $P C_{p 2}$ criterion finds eight significant factors, while the number of dynamic components is estimated at four. In addition, we performed the Alessi et al. (2010) improvement of the $P C_{p 2}$ criterion that in turn suggests nine factors.

After the static factors are estimated by principal components as in Stock and Watson (2002a), we report in Table 2 their marginal contribution to the variance of variables constituting UK-MD. For instance, $m R_{i}^{2}(k)$ measures the incremental explanatory power of the factor $k$ for the variable $i$, which is simply the difference between the $R^{2}$ after regressing the variable $i$ on the first $k$ and $k-1$ factors. The overall marginal contribution of the factor $k$ is the sample average over all variables. Table 2 shows the average $m R^{2}(k)$ for each of nine estimated factors, lists ten series that load most importantly on each factor and indicates the group to which the series belongs. For example, factor 1 explains $20.7 \%$ of the variation in UK-MD and is clearly a real activity factor as the ten most related variables are indicators of production and services. In particular, it explains 88.7 and $83.6 \%$ of variation in the index of services and the index of production in manufacturing respectively. The second factor explains $8.4 \%$ of variation overall, and represents mainly the group of interest rates. For instance, its marginal contribution to the 12-month LIBOR is 0.532. Factor 3's average explanatory power is $5.4 \%$ and it is linked to prices indices, with the highest $m R_{i}^{2}(k)=0.513$ for the CPI inflation. Factors 4 and 5 are related to stock market and employment variables respectively. The sixth factor explain $3.4 \%$ of total variation and can be interpreted as the international trade factor. Factor 7 is related to unemployment and working hours indicators, with an explanatory power of $24.5 \%$ for the over 12 month unemployment duration. Exchange rates are well explained by the seventh factor. Finally, the ninth component stands out as an energy factor as it explains a sizeable fraction of variation in production indices of oil extraction, mining and energy sectors.

Figure 1 plots the importance of the common component with nine factors. The total $R^{2}$ is 0.554 . The explanatory power of the common component varies across series. It explains more than $80 \%$ for 20 series, mostly services, production and average week hours series. The nine factors are also 
Table 2: Interpretation of factors estimated from UK-MD, 1998M1-2020M9

\begin{tabular}{|c|c|c|c|c|c|c|c|c|}
\hline$m R^{2}(1)$ & 0,207 & G\# & $m R^{2}(2)$ & 0,084 & G\# & $m R^{2}(3)$ & 0,054 & G\# \\
\hline IOS & 0,887 & 3 & LIBOR_12mth & 0,532 & 6 & CPI_ALL & 0,513 & 4 \\
\hline IOP_MANU & 0,836 & 2 & LIBOR_3mth & 0,486 & 6 & CPIH_ALL & 0,466 & 4 \\
\hline AVḠW_RET_SALE_NF & 0,810 & 3 & RPI_ALL & 0,469 & 4 & CPI_EX_ENER & 0,392 & 4 \\
\hline IOP_PROD & 0,802 & 2 & LIBÖR_1mth & 0,418 & 6 & CPI_GOODD & 0,391 & 4 \\
\hline IOS_PNDS & 0,786 & 3 & BANK_RATE & 0,411 & 6 & RPI_GOOD & 0,238 & 4 \\
\hline CLI & 0,781 & 8 & BGS_5yrs_yld & 0,366 & 6 & PPI_MANU & 0,185 & 9 \\
\hline IOP_INT_GOOD & 0,770 & 2 & RPI_GOOD & 0,308 & 4 & RPI_ALL & 0,182 & 4 \\
\hline IOS_45 & 0,768 & 3 & BGS_10yrs_yld & 0,287 & 6 & EMP_RATE & 0,171 & 1 \\
\hline IOS_G & 0,765 & 3 & PPI_MANU & 0,284 & 9 & RPI_SERV & 0,171 & 4 \\
\hline IOP_CAP_GOOD & 0,765 & 2 & MORT_FRATE_2YRS & 0,269 & 6 & CPI_TRANS & 0,169 & 4 \\
\hline$m R^{2}(4)$ & 0,045 & G\# & $m R^{2}(5)$ & 0,038 & G\# & $m R^{2}(6)$ & 0,034 & G\# \\
\hline FTSE250 & 0,432 & 7 & EMP & 0,257 & 1 & EXP_GOOD & 0,338 & 5 \\
\hline FTSE_ALL & 0,386 & 7 & EMP_ACT_RATE & 0,209 & 1 & EXP_TOT & 0,290 & 5 \\
\hline SP500 & 0,385 & 7 & EMP_RATE & 0,197 & 1 & IMP_GOOD & 0,197 & 5 \\
\hline UK_focused_equity & 0,360 & 7 & EMP_ACT & 0,188 & 1 & IMP_FUEL & 0,188 & 5 \\
\hline EMP & 0,245 & 1 & FTSE_ALL & 0,177 & 7 & EXP_FUEL & 0,175 & 5 \\
\hline EMP_RATE & 0,210 & 1 & FTSE250 & 0,175 & 7 & IMP_ALL & 0,160 & 5 \\
\hline EUR_UNC_INDEX & 0,159 & 7 & UK_focused_equity & 0,144 & 7 & EXP_MACH & 0,153 & 5 \\
\hline EMP_PART & 0,152 & 1 & M4 & 0,142 & 6 & IMP_OIL & 0,143 & 5 \\
\hline EMP_ACT & 0,152 & 1 & MORT_FRATE_2YRS & 0,138 & 6 & EXP_OIL & 0,133 & 5 \\
\hline EMP_ACT_RATE & 0,131 & 1 & LIBOR_12mth & 0,128 & 6 & IMP_MACH & 0,111 & 5 \\
\hline$m R^{2}(7)$ & 0,033 & G\# & $m R^{2}(8)$ & 0,032 & G\# & $m R^{2}(9)$ & 0,027 & G\# \\
\hline UNEMP_DURA_12mth & 0,245 & 1 & GBP_CAN & 0,277 & 5 & IOP_OIL_EXTRACT & 0,530 & 2 \\
\hline AVG_WEEK_HRS_FULL & 0,186 & 1 & GBP_BROAD & 0,264 & 5 & IOP_MINE & 0,522 & 2 \\
\hline AVG_WEEK_HRS & 0,185 & 1 & GBP_EUR & 0,222 & 5 & IOP_ENER & 0,469 & 2 \\
\hline TOT_WEEK_HRS & 0,132 & 1 & EXP_FUEL & 0,125 & 5 & EXP_OIL & 0,138 & 5 \\
\hline EMP_RATE & 0,132 & 1 & M1 & 0,120 & 6 & EXP_FUEL & 0,101 & 5 \\
\hline UNEMP_DURA_24mth & 0,130 & 1 & PPI_MACH & 0,111 & 9 & IMP_CRUDE_MAT & 0,089 & 5 \\
\hline UNEMP_RATE & 0,128 & 1 & FTSE_ALL & 0,111 & 7 & IMP_METAL & 0,088 & 5 \\
\hline AWE_PRIV & 0,124 & 1 & EXP_OIL & 0,108 & 5 & EXP_MACH & 0,064 & 5 \\
\hline VAC_TOT & 0,124 & 1 & PPI_MOTOR & 0,095 & 9 & EXP_CRUDE_MAT & 0,050 & 5 \\
\hline AWE_ALL & 0,109 & 1 & SP500 & 0,095 & 7 & EXP_METAL & 0,043 & 5 \\
\hline
\end{tabular}

Note: This table shows the ten series that load most importantly on the first nine factors. For example, the first factor explains $20.7 \%$ of the variation in all 112 series, and it explains $88.7 \%$ of variation in IOS indicator. The third column of each panel indicates the group to which the variable belongs. Group 1: labour market. Group 2: production. Group 3: retail and services. Group 4: consumer and retail price indices. Group 5: international trade. Group 6: money, credit and interest rates. Group 7: stock market. Group 8: sentiment and leading indicators. Group 9: producer price indices.

very important for 42 variables as they have an $R^{2}$ between 0.5 and 0.8 . There is only one series that have the idiosyncratic component explaining over $90 \%$ of the variation, IOP_PETRO, and 3 variables for which the common component $R^{2}$ is less than $20 \%$. Therefore, we can conclude that the factor structure in UK-MD seems reasonable and is comparable to those in FRED-MD and CAN-MD datasets. Interestingly, the interpretation of the first three UK-MD factors is identical to the interpretation of the first three FRED-MD components.

In Figure 2 we show the number of static factors selected recursively from 2009 by the Bai and $\mathrm{Ng}$ (2002) $P C_{p 2}$ criterion (upper panel) and the corresponding $R^{2}$ (bottom panel). The number of significant factors increases over time. It goes from 2 between 2009 and 2015, followed by a second plateau at 4 until 2020, and it jumps to 7, 9 and 8 since the Covid-19 pandemic. The additional factors emerging during the pandemic period are likely capturing the specificities of this period. 
Figure 1: Importance of factors

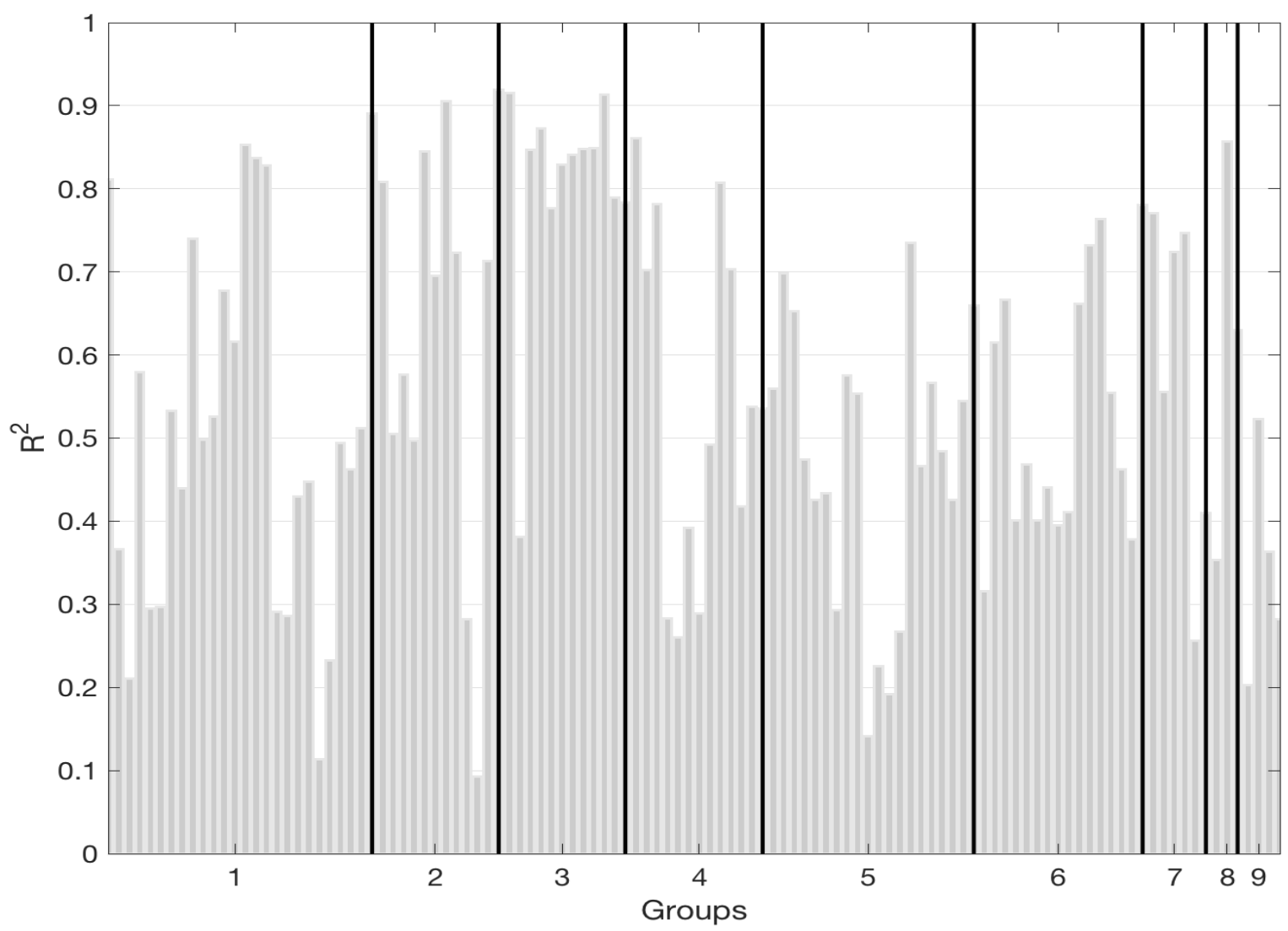

Note: This figure illustrates the explanatory power of the first nine factors in the UK-MD series organized into nine groups. Group 1: labour market. Group 2: production. Group 3: retail and services. Group 4: consumer and retail price indices. Group 5: international trade. Group 6: money, credit and interest rates. Group 7: stock market. Group 8: sentiment and leading indicators. Group 9: producer price indices.

\section{Empirical Setup}

\subsection{Variables of Interest}

We focus on predicting twelve representative macroeconomic indicators of the UK economy: Employment (EMP), Unemployment rate (UNEMP RATE), Total actual weekly hours worked (HOURS), Industrial Production (IP PROD), Index of production: manufacture of machinery and equipment (IP MACH), Total retail trade (RETAIL), Consumer price index (CPI), Retail price index (RPI), RPI Housing (RPI HOUSING), Consumer credit excluding student loans (CREDIT), Total sterling approvals for house purchases (HOUSE APP) and Producer price index of manufacturing sector (PPI MANU).

We consider the direct predictive modeling in which the target is projected on the information set, and the forecast is made directly using the most recent observables. All the variables above are 
Figure 2: Number of factors and $R^{2}$ over time
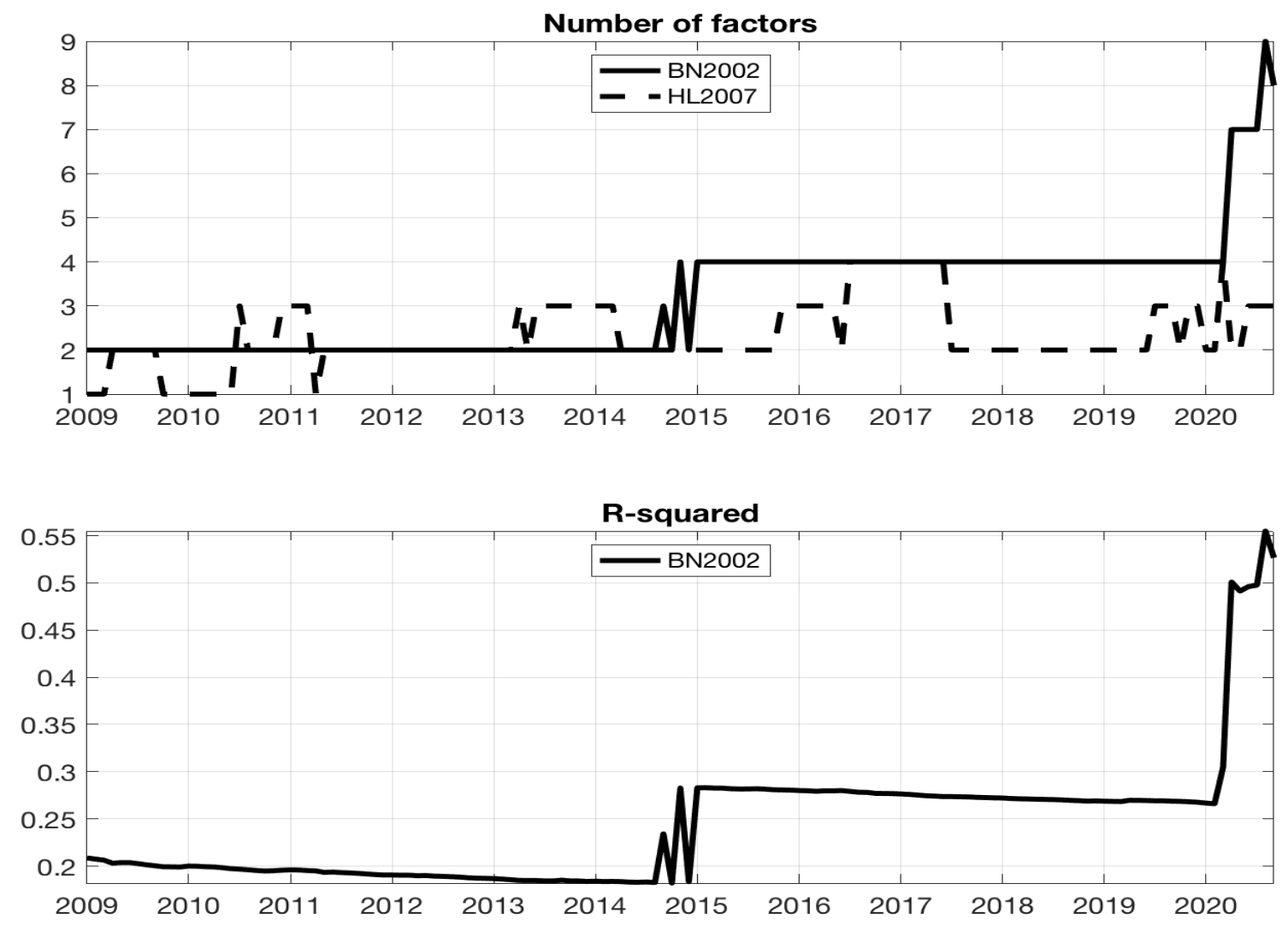

Note: This figure plots the number of factors selected recursively since 2009 by the Bai and $\mathrm{Ng}(2002) P C_{p 2}$ criterion (upper panel) and the corresponding total $R^{2}$ (bottom panel).

assumed $I(1)$, so we forecast the average growth rate (Stock and Watson, 2002b),

$$
y_{t+h}^{(h)}=(1 / h) \ln \left(Y_{t+h} / Y_{t}\right)
$$

except for UNRATE where we target the average change as in (6) but without logs.

\subsection{Pseudo-Out-of-Sample Experiment Design}

The pseudo-out-of-sample period starts on 2008M01. The end period depends on target variables. Labor market series, EMP, UNEMP RATE and HOURS, end on 2020M09, while RETAIL is available up to 2020M10. The rest of variables end on 2020M11. The forecasting horizons considered are 1, 2 and 3 months. All models are estimated recursively with an expanding window in order to include more data so as to potentially reduce the variance of more flexible models.

The standard Diebold and Mariano (2002) (DM) test procedure is used to compare the predictive accuracy of each model against the reference autoregressive model. Mean squared error (MSE) is the most natural loss function given that all models are trained to minimize the squared 
Table 3: Best COVID era Models (as displayed in Figure 3)

\begin{tabular}{|c|c|c|c|c|c|}
\hline & \multicolumn{4}{|c|}{ Variables } \\
\hline & & EMP & HOURS & RPI HOUSING & PPI MANU \\
\hline \multirow{3}{*}{ Models } & Best Linear & RW & RIDGE+MARX & RW & E-NET+MARX \\
\hline & Best Nonlinear & FA-ARRF, 2Fac & FA-ARRF, 4Fac & ARRF, 6Ylag & RF+MARX \\
\hline & Best Overall Pre-Covid & RIDGE+MARX & NN-ARDI & LASSO+MARX & E-NET \\
\hline
\end{tabular}

loss in-sample. Hyperparameter selection is performed using the BIC for AR and ARDI and K-fold cross-validation is used for the remaining models. This approach is theoretically justified in time series models under conditions spelled out by Bergmeir et al. (2018). Moreover, Goulet Coulombe et al. (2019) compared it with a scheme which respects the time structure of the data in the context of macroeconomic forecasting and found K-fold to be performing as well as or better than this alternative scheme. All models are estimated (and their hyperparameters re-optimized) every month.

\section{Results}

In this section we present the results of the forecasting experiment, focusing first on the Covid19 era and then on average performance over the longer evaluation sample.

\subsection{Pandemic Recession Case Study}

Figure 3 looks at four selected cases and compares the behavior of the best models among certain categories: best linear model for the Covid era, defined as the period 2020M1-2020M9/M11 depending on the variable, best nonlinear model for the Covid era, and best model overall for the 2008-2019 period. The exact identities of selected models in Figure 3 are reported in Table 3.

Though the Covid era is short and so the results should be interpreted with care, the outcome is quite interesting. Linear models have a hard time characterizing the path of EMP during the Pandemic recession. Ridge+MARX, which was marginally better than the nonlinear FA-ARRF $(2,2)$ during the pre-Covid era, is predicting an employment cataclysm that did not materialize. This is a general property of linear models for this target since the best linear forecast (other than the AR) for EMP in 2020 is the 0 forecast, that is, the RW without drift in levels. FA-ARRF(2,4) (and FA$\operatorname{ARRF}(2,2)$ close behind) is the best model for EMP at a horizon of one month. At longer horizons, RF-MARX is the best model, with a decisive advantage over both AR and RF that do not use the transformations of Goulet Coulombe et al. (2020). This winning streak extends to unemployment at all horizons - another variable that responded in a rather mild fashion to the Covid shock due to Government intervention. Given RF usual robustness (Goulet Coulombe, 2020b), those gains are almost all statistically significant.

In Figure 3b, we see that the improvement at $h=1$ comes from responding more swiftly (and more vigorously) to the first Covid shock than what AR would allow for. An explanation for 
this well-calibrated response can be found in Figure 4 which plots the underlying Generalized Time-Varying Parameters (GTVPs) for FA-ARRF $(2,2)$. The persistence seems to be highly statedependent — being much higher during certain episodes (including recessions). This feature is replicated out-of-sample during the Pandemic recession, which procured FA-ARRF $(2,2)$ an edge over the competitive plain AR. Additionally, the model incorporates an intercept that alternates between two regimes, with the negative one being attributed to recessions (but not exclusively according to pre-2008 data). The drop in intercept is also predicted out-of-sample for the Covid period. Unsurprisingly, those switches match those of persistence. Finally, it is noted that the sensitivity to the first factor (which usually characterizes real activity) is initially milder during recessions for EMP. This is a salient feature for 2020 as the EMP response to the Covid shock is much milder than that of other labor/production indicators (like HOURS).

Turning to HOURS - which experienced an unprecedented rise and fall during the onset of the Pandemic Recession -, it is striking to see that only Macroeconomic Random Forests (MRF) can beat the AR benchmark at $h=1$. Indeed, the four MRFs report MSE ratios between 0.69 and 0.78 whereas that of the other nonlinear models range between 1.05 and 1.5. Things are even worse for linear models.

Figure 7 reports various variable importance (VI) measures for $\operatorname{FA}-\operatorname{ARRF}(2,2)$ (the reader is referred to Goulet Coulombe (2020a) for numerous implementation details). Universally, the VIs suggest the predominance of other labor indicators like measures of vacancies. Given how those are closely related to HOURS itself, and that all successful MRFs include an AR component, this points in the direction that HOURS may well follow a nonlinear AR process which MRF is particularly well equipped to extract. As a result, the response of MRF to the Covid shock is (as it was the case for EMP), more timely than that of AR. Given how fast things were evolving back in the spring of 2020, that timing provides MRF with an improvement of around 30\% over the benchmark.

As conjectured earlier, MRF's capacity to extrapolate (which RF and Boosted Trees both lack) proves vital for variables which exhibited (previously unseen) swings of extraordinary proportions. While NN-ARDI also has the capacity to extrapolate (and is marginally better than FA$\operatorname{ARRF}(2,2)$ in the pre-Covid era), its lack of an explicit linear part is likely to blame for its spectacular incapacity to propel the Covid shock in Figure 3b. A similar dismal predicament is observed for RIDGE-MARX which is the best linear model for the Covid sample.

Different troubles afflict data-rich linear models for RPI HOUSING with MSE ratios exploding well over 10. As a result, the best linear model is without question the simple autoregression. An obvious explanation for the generalized failure of linear models (and also most data-rich ones) can be found in Figure 3b. The "orange" forecasts basically predict a path largely inspired by the experience of the Great Recession, i.e., a joint collapse of real activity and housing prices. Since this is the sole recession in the training set, it is fair to say that most ML methods naively (yet inevitably) associate real activity slowdown with a significant drop in RPI Housing. However, by information available to the economist, but not to the sample-constrained ML algorithm, this 

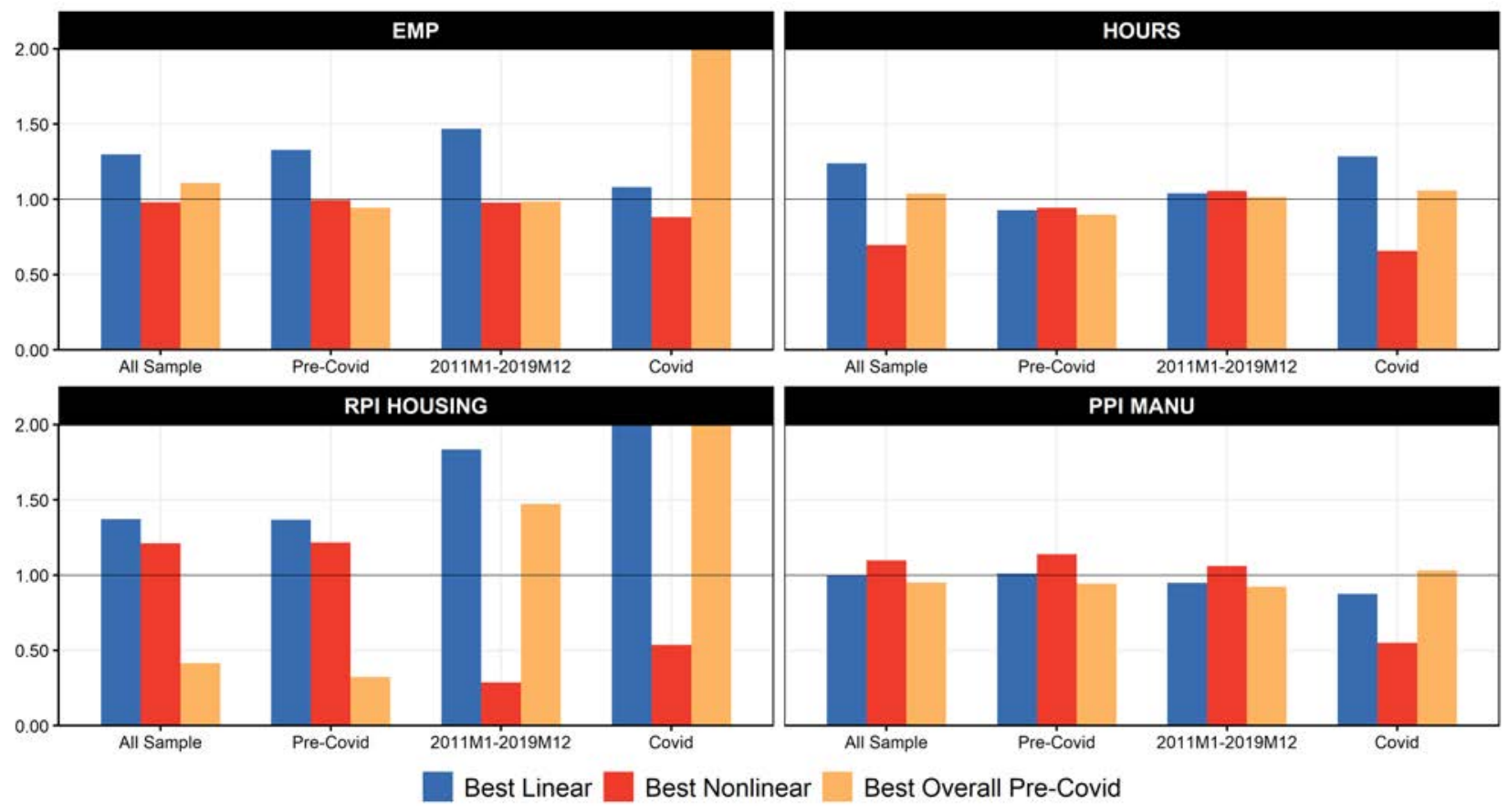

(a) MSEs wrt $\operatorname{AR}(p)$
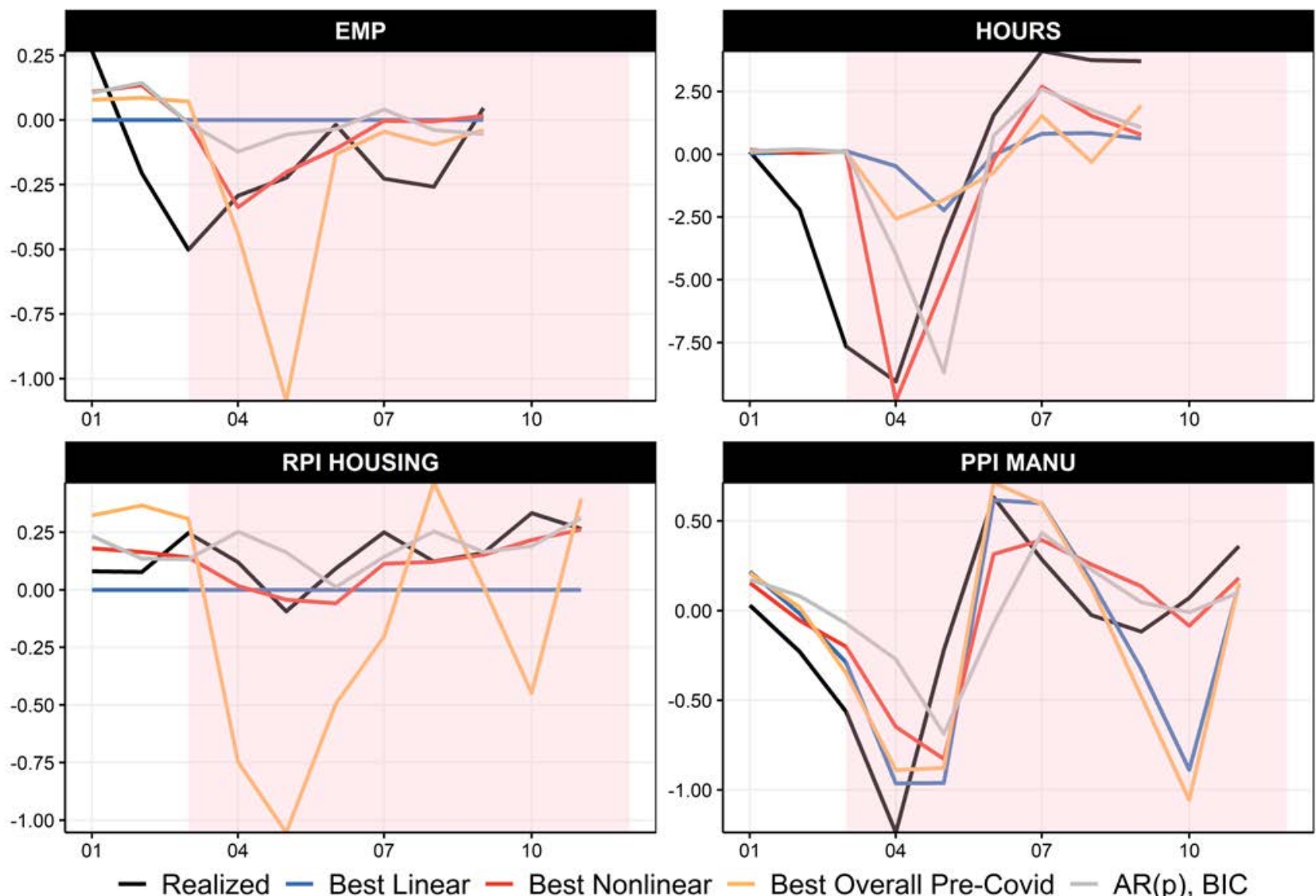

(b) Forecasts from January 2020

Figure 3: Best Models for Four Selected Targets 
Figure 4: GTVPs of FA-ARRF(2,2) - EMP at $h=1$
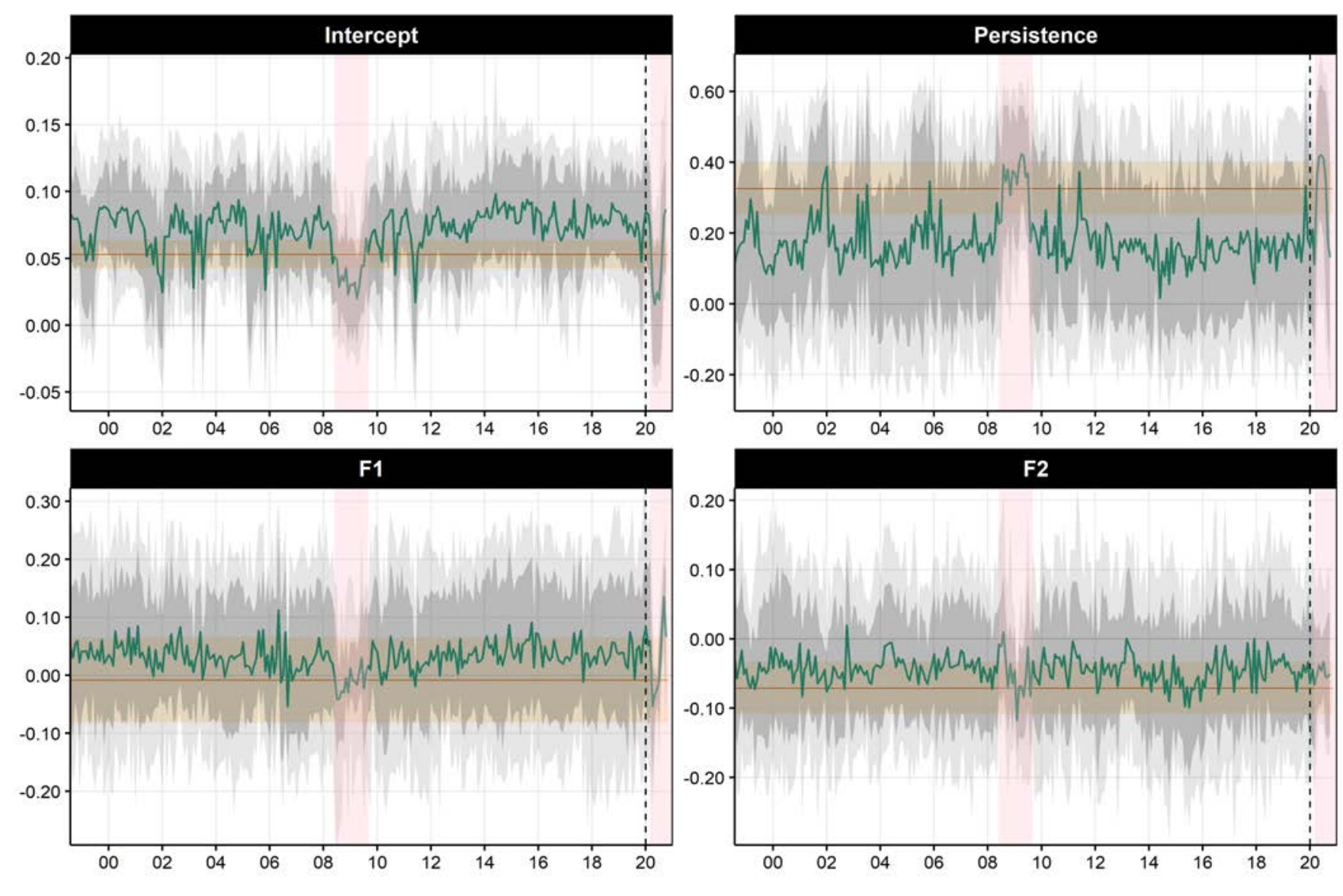

- GTVP - OLS

Notes: GTVPs of the one month ahead EMP forecast. Persistence is defined as the sum of $y_{t-1: 2}$ 's coefficients. The gray bands are the $68 \%$ and $90 \%$ credible region. The pale orange region is the OLS coefficient \pm one standard error. The vertical dotted line is the end of the training sample (for this graph only, not the forecasting exercise itself, which is ever-updating). Pink shading corresponds to recessions.

association is more of a 2008-2009 exception than a "rule".

The only models able to beat the benchmark are the MRFs equipped with small autoregressions as linear parts $(\operatorname{ARRF}(2)$ and $\operatorname{ARRF}(6))$. So, how did they avoid the dismal fates of other ML methods, and captured nicely the soft drop (and bounce back) of RPI HOUSING in 2020? First, they do not rely explicitly on linkage with other groups of variables (like FA-ARRFs would through the use of factors) but rather focus on nonlinear autoregressive dynamics. This strategy is expected to pay off whenever a shock can truly be thought of as "exogenous" and we simply need a model to propagate it - this description corresponds to the onset of the Pandemic Recession but certainly not its predecessor. Second, the model needs to separate pre-2008 dynamics from what followed. Figure 5 report interesting transformations of ARRF(6)'s GTVPs. While persistence is rather stable at 0.75 , the long-run mean is subject to a lot of variation. Some is cyclical (like the mild drops in 2008 and 2020), but the most noticeable feature is a permanent regime change after 2008. Variable 
Figure 5: GTVPs of ARRF(6) - RPI HOUSE at $h=1$

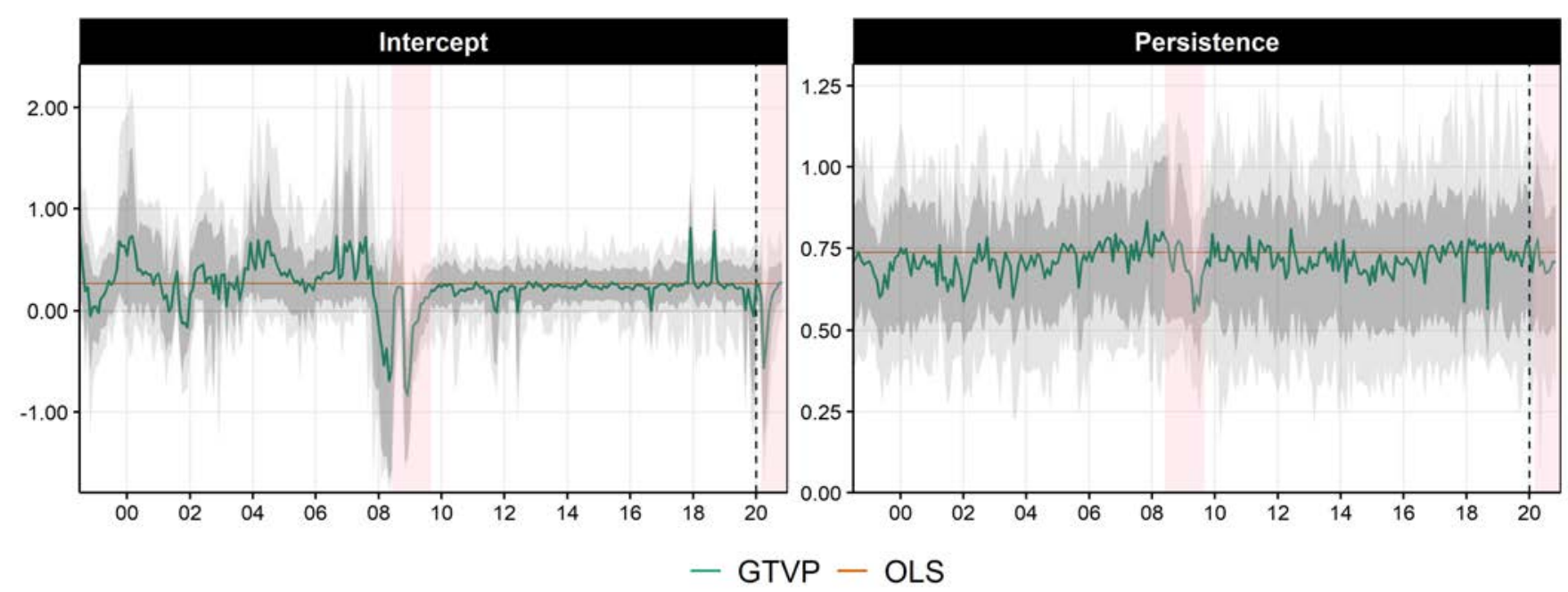

Notes: GTVPs of the one month ahead EMP forecast. Persistence is defined as the sum of $y_{t-1: 6}$ 's coefficients. The reported intercept is the long-run mean. The gray bands are the $68 \%$ and $90 \%$ credible region. The pale orange region is the OLS coefficient \pm one standard error. The vertical dotted line is the end of the training sample (for this graph only, not the forecasting exercise itself, which is ever-updating). Pink shading corresponds to recessions.

importance measures in Figure 8 validate this observation: much of the forest generating the timevariation uses either "trend" (i.e., exogenous change) or a catalog of indicators related to the policy rate (UK Bank Rate, US Federal Funding Rate, and many MARX transformations of those) whose are known to have entered uncharted territory in the aftermath of the 2008-2009 recession. Figure 9 confirms visually that the variation in the intercept of $\mathrm{ARRF}(6)$ gives an edge over both AR and the best linear model (RIDGE-MARX), especially starting from 2011. As a result, ARRF(6) is also the best model for all horizons in the quieter period of 2011-2019 (see Table 11) with improvements over the AR benchmark of $70 \%, 54 \%$ and $54 \%$ at horizons 1 to 3 respectively.

The last quadrant of Figure 3a shows that for PPI MANU, a model that does marginally worse most of the time can generate substantial gain during the Covid period. Such is the case for RFMARX which performance is similar to that of the best linear model for most samples (and the best overall pre-Covid). Figure 3b makes clear that this edge during the Pandemic happens because (i) RF-MARX goes almost as deep as linear models during the spring and yet (ii) does not call for a large decrease in September and October (unlike linear models, and akin to AR's prediction). Since RF-MARX does better than plain RF by $36 \%$ and Boosting-MARX better than plain Boosting by $12 \%$, it is natural curiosity to investigate the VI measures of those models to uncover what particular MARX transformations RF is so fond of. In Figure 6, we see that both plain Boosting and RF rely strongly on the most recent values of oil prices, PPI oil and PPI MANU itself - which comes to no surprise. Interestingly, the other lags of oil prices are generally absent from the top 20. The MARX versions consider a slightly less focused set of predictors composed of various moving 
Figure 6: Variable Importance for RF and Boosting — PPI MANU at $h=1$
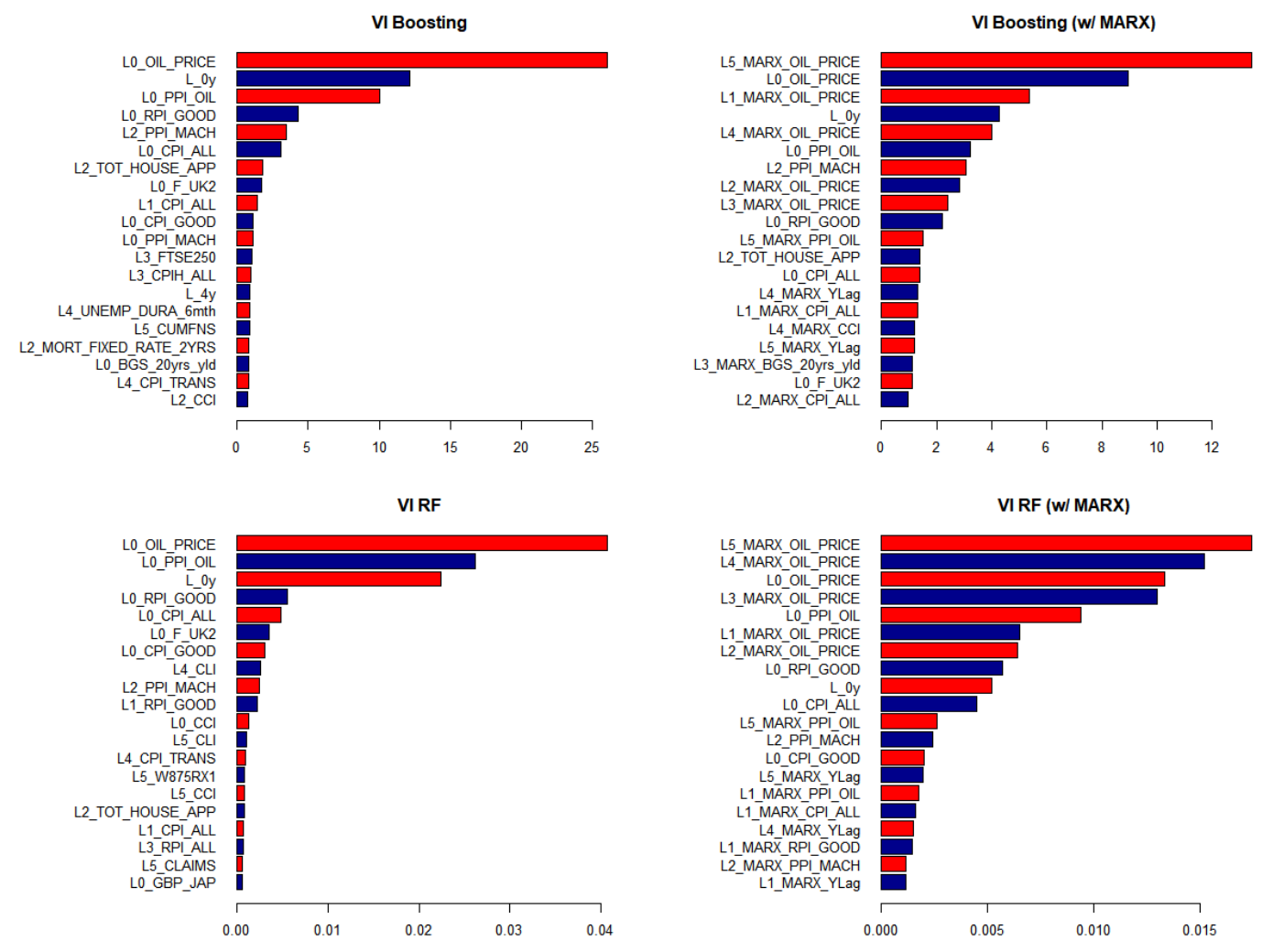

Note: Comparing Variable Importance for Boosting and RF, with and without MARX, when forecasting PPI MANU at a one-month horizon.

averages of oil prices. In both the RF and Boosting case, the most important feature is the last 6 months average of oil prices change. Thus, RF-MARX versions avoid calling for another decrease of PPI MANU by relying less on monthly oil indicators by themselves, which are subject to large swings, but rather on temporal averages that have the ability of smoothing out the noise inevitably present in the oil price trajectory. Moreover, by the very design of the manufacturing production chain, increases/decreases over several months are more likely to be transmitted into prices than notoriously volatile one-month-to-the-next variations.

\subsection{Quiet(er) Times}

It has been repeatedly reported that the benefits of a large panel of predictors may solely be present during periods of economic turmoil (Kotchoni et al., 2019; Siliverstovs and Wochner, 2019). For this reason and others (Lerch et al., 2017), it is of interest to study the marginal benefits associated with data-rich models outside of the tumultuous entry/exit of the Great Recession and the Pandemic Recession. Moreover, starting the pseudo-out-of-sample from 2011 gives data-rich models at least one recession to be trained on, and 13 years of data overall rather than 10 (as it were the case in Table 4).

Ridge and Ridge-MARX do well for EMP and HOURS with gains roughly distributed between 
$10 \%$ and $20 \%$ depending on the horizon. The MARX version usually has the upper hand by a small margin. The evidence for other activity indicators is more mixed. For HOURS, only nonlinear models manage to beat the AR benchmark albeit in a non-statistically significant fashion. The best model for IP PROD at all horizons is $\mathrm{ARRF}(2)$ which improves upon the AR by small margins. For IP MACH, some small gains can be obtained at a horizon of 3 months (with FA-ARRF(2,2), most notably) but none of those are statistically significant.

Aligned with traditional wisdom for the US (Stock and Watson, 2008), it is hard to beat the simple benchmark when it comes to CPI inflation. Nevertheless, ARRF(6) is the best model for all horizons (ex-aequo at $h=1$ ) with gains of $9-10 \%$ - but none of those are significant. Larger improvements are obtained for RPI, where various data-rich models (linear and nonlinear) provide gains of around $20 \%$. The most notable are those of FA-ARRFs at a horizon of 3 months (but also any other horizon) which are nearly $30 \%$, far ahead from most of the competing models including all those that also rely directly on factors. Finally, as a last notable observation from Table 11, ARRF(6) dominates at all horizons for both RPI HOUSING and CREDIT, highlighting the benefits of a more focused modeling of persistence (while allowing for its time variation) in otherwise high-dimensional/data-rich/nonlinear ML methods.

\section{Conclusion}

In this paper we assess the forecasting performance of a variety of standard and ML forecasting methods for key UK economic variables, with a special focus on the Covid-19 period and using a specifically collected large dataset of monthly indicators, labeled UK-MD (also augmented with some international indicators).

As standard benchmarks, we consider AR, random walk and factor augmented AR models. As ML methods, we evaluate penalized regressions (RIDGE, LASSO, ELASTIC NET), boosted trees (BT) and random forests (RF), Kernel Ridge Regression (KRR), and Neural Networks (NN), plus Macroeconomic Random Forest (MRF), which uses a linear part within the leafs, and Moving Average Rotation of $X$ (MARX), a feature engineering technique which generates an implicit shrinkage more appropriate for time series data.

Overall ML methods can provide substantial gains when short-term forecasting several indicators of the UK economy, though a careful temporal and variable by variable analysis is needed. Over the full sample, RF works particularly well for labour market variables, in particular when augmented with MARX; KRR for real activity and consumer price inflation; LASSO or LASSO+MARX for the retail price index and its version focusing on housing; and RF for credit variables. The gains can be sizable, even $40-50 \%$ with respect to the benchmark, and ML methods were particularly useful during the Covid-19 period. During the Covid era, nonlinear methods with the ability to extrapolate have a nice edge. Certain MRFs, unlike linear methods or simpler nonlinear ML techniques, procure important improvements by predicting large "bounce back" that did occur and avoid predicting mayhem that did not materialize. 


\section{References}

Alessi, L., Barigozzi, M., and Capasso, M. (2010). Improved penalization for determining the number of factors in approximate factor models. Statistics and Probability Letters, 80(23-24):18061813.

An, Z. and Loungani, P. (2020). How well do economists forecast recoveries. Technical report, IMF Working Paper, 20 April.

Bai, J. and Ng, S. (2002). Determining the number of factors in approximate factor models. Econometrica, 70(1):191-221.

Banbura, M., Giannone, D., and Reichlin, L. (2008). Large Bayesian VARs. Technical report, Working Paper Series 966, European Central Bank.

Bergmeir, C., Hyndman, R. J., and Koo, B. (2018). A note on the validity of cross-validation for evaluating autoregressive time series prediction. Computational Statistics E Data Analysis, 120:7083.

Bernanke, B., Boivin, J., and Eliasz, P. (2005). Measuring the effects of monetary policy: a factoraugmented vector autoregressive (FAVAR) approach. Quarterly Journal of Economics, 120:387-422.

Boivin, J. and Giannoni, M. (2006). DSGE models in a data-rich environment. Technical report, Columbia Business School, Columbia University.

Breiman, L. (2001). Random forests. Machine learning, 45(1):5-32.

Carriero, A., Clark, T., and Marcellino, M. (2020). Nowcasting tail risks to economic activity with many indicators. Technical report, Cleveland FED WP 20-13.

Clark, T., Huber, F., Koop, G., Marcellino, M., and Pfarrhofer, M. (2021). Tail forecasting with bayesian additive regression trees. Technical report, mimeo.

Clements, M. P. and Hendry, D. F. (1999). Forecasting Non-Stationary Economic Time Series. Cambridge, U.K.

Dendramis, Y., Kapetanios, G., and Marcellino, M. (2020). A similarity-based approach for macroeconomic forecasting. Journal of the Royal Statistical Society, Series A, forthcoming.

Diebold, F. X. and Mariano, R. S. (2002). Comparing predictive accuracy. Journal of Business $\mathcal{E}$ economic statistics, 20(1):134-144.

Ferrara, L., Marcellino, M., and Mogliani, M. (2015). Macroeconomic forecasting during the great recession: The return of non-linearity? International Journal of Forecasting, 31:664-679.

Foroni, C., Marcellino, M., and Stevanovic, D. (2020). Forecasting the covid-19 recession and recovery: Lessons from the financial crisis. International Journal of Forecasting.

Fortin-Gagnon, O., Leroux, M., Stevanovic, D., and Surprenant, S. (2018). A large canadian database for macroeconomic analysis. Technical report, CIRANO Working Papers, 2018s-25. 
Goulet Coulombe, P. (2020a). The macroeconomy as a random forest. arXiv preprint arXiv:2006.12724.

Goulet Coulombe, P. (2020b). To bag is to prune. arXiv e-prints, pages arXiv-2008.

Goulet Coulombe, P., Leroux, M., Stevanovic, D., and Surprenant, S. (2019). How is machine learning useful for macroeconomic forecasting? Technical report, CIRANO Working Papers, 2019s-22.

Goulet Coulombe, P., Leroux, M., Stevanovic, D., and Surprenant, S. (2020). Macroeconomic data transformations matter. arXiv preprint arXiv:2008.01714.

Gu, S., Kelly, B., and Xiu, D. (2019). Empirical asset pricing via machine learning. Review of Financial Studies.

Hallin, M. and Liska, R. (2007). Determining the number of factors in the general dynamic factor model. Journal of the American Statistical Association, 102:603-617.

Hastie, T., Tibshirani, R., and Friedman, J. (2009). The elements of statistical learning: data mining, inference, and prediction. Springer Science \& Business Media.

Huber, F., Koop, G., Onorante, L., Pfarrhofer, M., and Schreiner, J. (2020). Nowcasting in a pandemic using non-parametric mixed frequency vars. arXiv preprint arXiv:2008.12706.

Joseph, A., Kalamara, E., Potjagailo, G., and Kapetanios, G. (2021). Forecasting uk inflation bottom up. Technical report, mimeo.

Kotchoni, R., Leroux, M., and Stevanovic, D. (2019). Macroeconomic forecast accuracy in a datarich environment. Journal of Applied Econometrics, 34(7):1050-1072.

Kruskal, W. H. and Wallis, W. A. (1952). Use of ranks in one-criterion variance analysis. Journal of the American statistical Association, 47(260):583-621.

Lerch, S., Thorarinsdottir, T. L., Ravazzolo, F., and Gneiting, T. (2017). Forecaster?s dilemma: Extreme events and forecast evaluation. Statistical Science, 32(1):106-127.

Mao Takongmo, C. and Stevanovic, D. (2015). Selection of the number of factors in presence of structural instability: a monte carlo study. Actualité Économique, 91:177-233.

McCracken, M. and Ng, S. (2020). FRED-QD: A quarterly database for macroeconomic research. Technical report, National Bureau of Economic Research.

McCracken, M. W. and Ng, S. (2016). FRED-MD: A monthly database for macroeconomic research. Journal of Business \& Economic Statistics, 34(4):574-589.

Plagborg-Møller, M., Reichlin, L., Ricco, G., and Hasenzagl, T. (2020). When is growth at risk? Brookings Papers on Economic Activity, forthcoming.

Schorfheide, F. and Song, D. (2020). Real-time forecasting with a (standard) mixed-frequency var during a pandemic. Technical report, Federal Reserve Bank of Philadelphia, Working Paper 
20-26.

Siliverstovs, B. and Wochner, D. (2019). Recessions as breadwinner for forecasters state-dependent evaluation of predictive ability: Evidence from big macroeconomic us data. KOF Working Papers, 463.

Stock, J. H. and Watson, M. W. (2002a). Forecasting using principal components from a large number of predictors. Journal of the American statistical association, 97(460):1167-1179.

Stock, J. H. and Watson, M. W. (2002b). Macroeconomic forecasting using diffusion indexes. Journal of Business \& Economic Statistics, 20(2):147-162.

Stock, J. H. and Watson, M. W. (2008). Phillips curve inflation forecasts. Technical report, National Bureau of Economic Research. 
A Detailed Forecasting Results 
Table 4: All Sample (2008-2020)

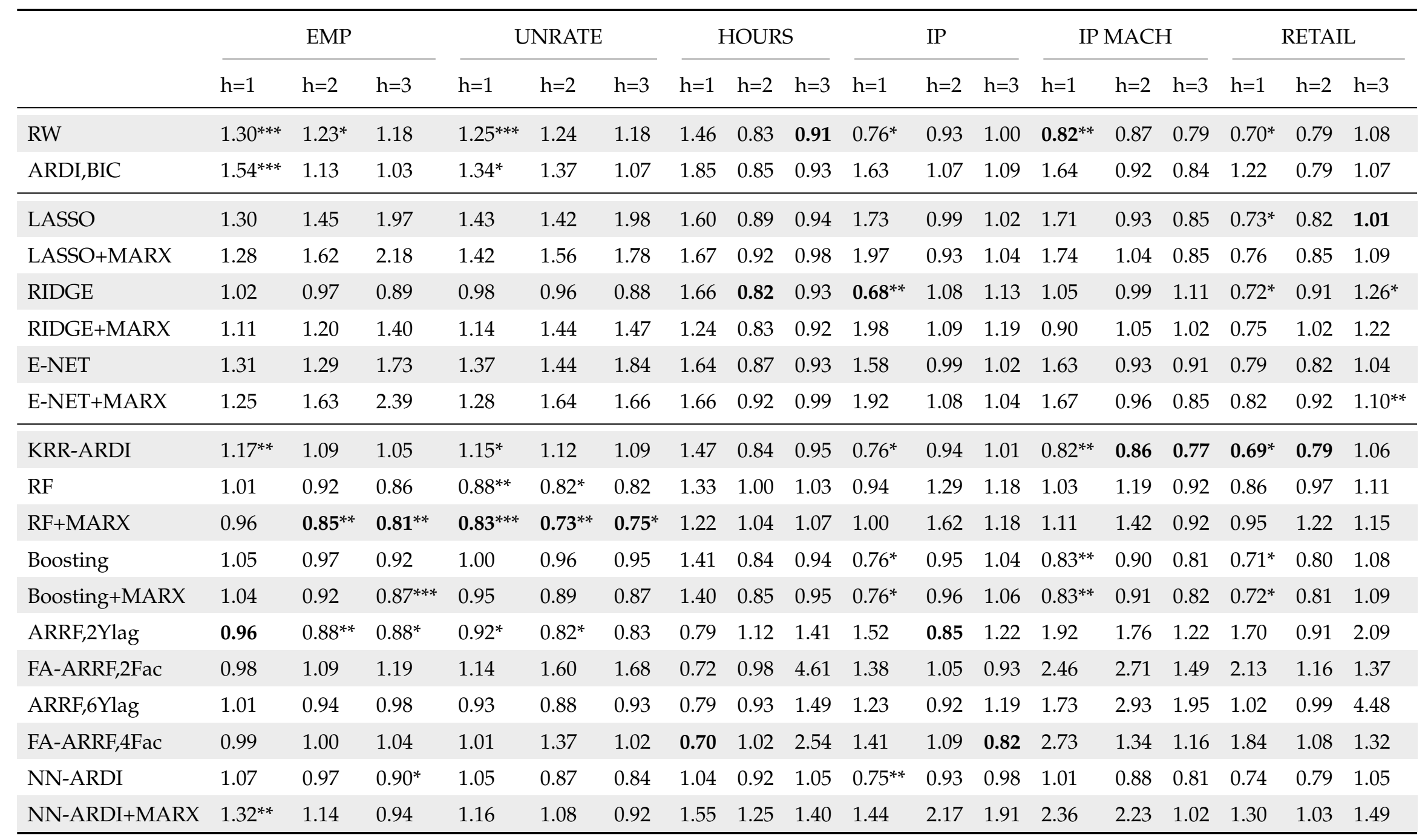

Notes: The numbers represent the relative MSEs with respect to AR,BIC model. ${ }^{* * *} .{ }^{* *} .{ }^{*}$ stand for $1 \% .5 \%$ and $10 \%$

significance of Diebold-Mariano test. 
Table 5: All Sample (2008-2020), Continued

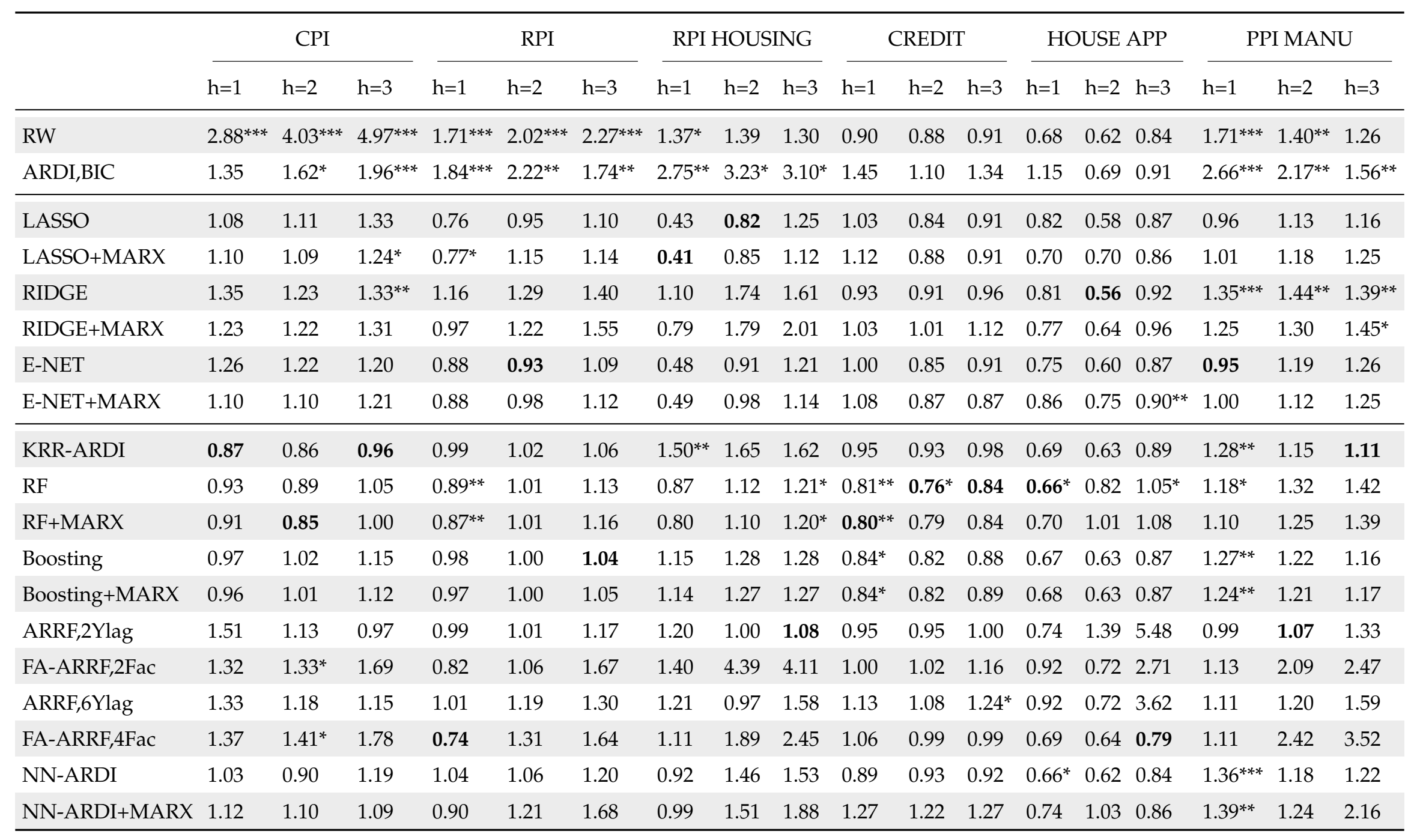

Notes: See Table 4. 
Table 6: Restricted Sample (2011-2020)

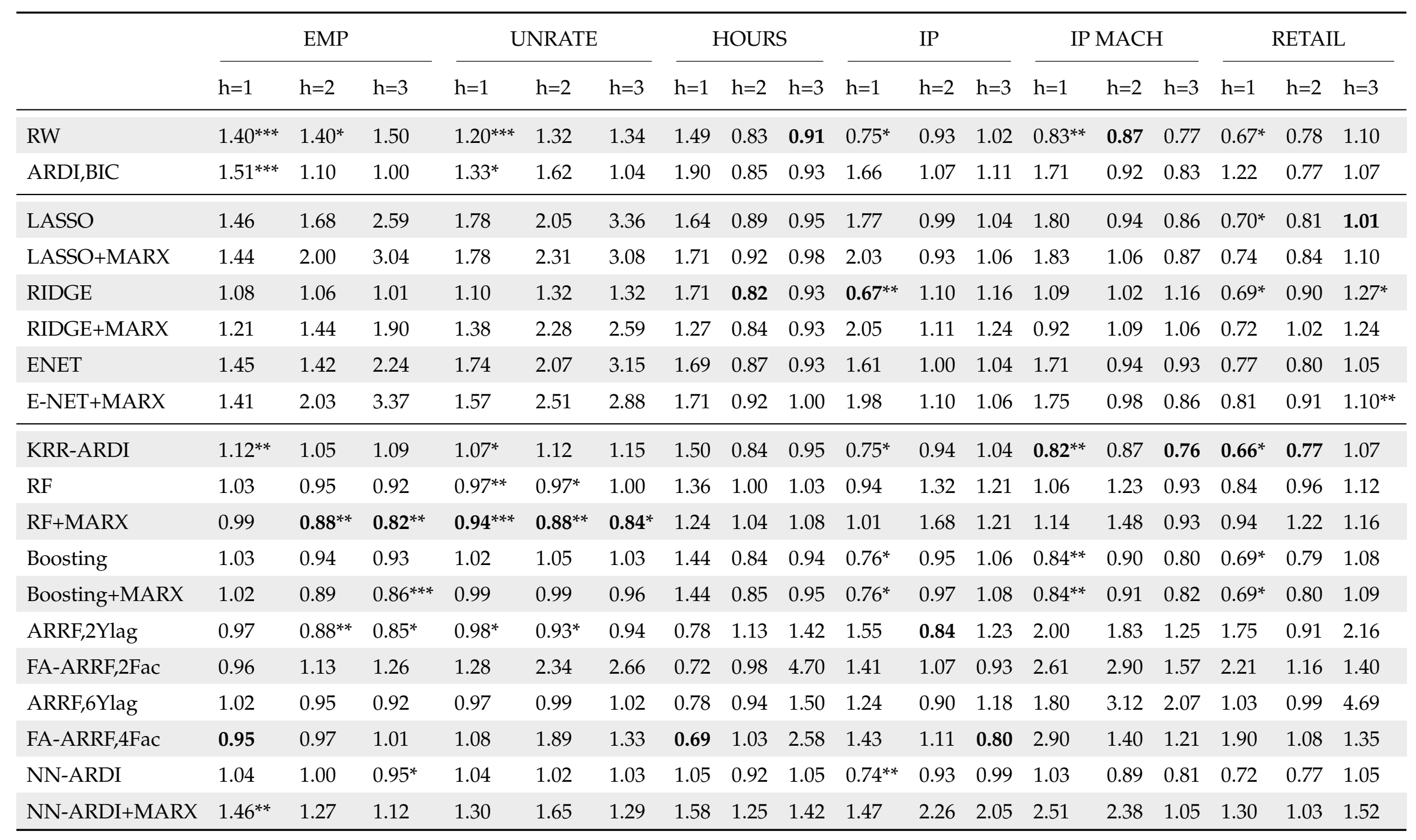

Notes: See Table 4. 
Table 7: Restricted Sample (2011-2020), Continued

\begin{tabular}{|c|c|c|c|c|c|c|c|c|c|c|c|c|c|c|c|c|c|c|}
\hline & \multicolumn{3}{|c|}{ CPI } & \multicolumn{3}{|c|}{ RPI } & \multicolumn{3}{|c|}{ RPI HOUSING } & \multicolumn{3}{|c|}{ CREDIT } & \multicolumn{3}{|c|}{ HOUSE APP } & \multicolumn{3}{|c|}{ PPI MANU } \\
\hline & $\mathrm{h}=1$ & $h=2$ & $h=3$ & $\mathrm{~h}=1$ & $h=2$ & $h=3$ & $\mathrm{~h}=1$ & $h=2$ & $h=3$ & $\mathrm{~h}=1$ & $\mathrm{~h}=2$ & $h=3$ & $\mathrm{~h}=1$ & $\mathrm{~h}=2$ & $h=3$ & $\mathrm{~h}=1$ & $\mathrm{~h}=2$ & $h=3$ \\
\hline ARDI,BIC & 0.97 & $1.40^{*}$ & $2.05^{* * *}$ & $1.28^{* * *}$ & $2.34^{* *}$ & $1.77^{* *}$ & $3.29^{* *}$ & $11.50^{*}$ & $10.22^{*}$ & 3.20 & 1.53 & 2.35 & 1.14 & 0.64 & 0.83 & $1.79^{* * *}$ & $1.97^{* *}$ & $1.34^{* *}$ \\
\hline LASSO & 1.14 & 1.25 & 1.50 & 0.90 & 0.76 & 0.88 & 2.39 & 5.48 & 11.22 & 1.73 & 1.26 & 1.59 & 0.80 & 0.56 & 0.86 & 0.91 & 1.05 & 1.09 \\
\hline RIDGE & 1.70 & 1.48 & $1.37^{* *}$ & 1.36 & 1.51 & 1.49 & 4.45 & 16.54 & 16.48 & 1.44 & 1.53 & 1.71 & 0.80 & 0.55 & 0.93 & $1.37^{* * *}$ & $1.48^{* *}$ & $1.27^{* *}$ \\
\hline RIDGE+MARX & 1.47 & 1.49 & 1.49 & 1.16 & 1.35 & 2.15 & 3.08 & 18.27 & 26.05 & 1.60 & 1.62 & 2.00 & 0.77 & 0.64 & 0.98 & 1.31 & 1.40 & $1.52^{*}$ \\
\hline ENET & 1.53 & 1.47 & 1.21 & 0.90 & 0.74 & 0.88 & 2.53 & 6.80 & 10.18 & 1.50 & 1.32 & 1.56 & 0.73 & 0.59 & 0.87 & 0.94 & 1.06 & 1.09 \\
\hline E-NET+MARX & 1.16 & 1.17 & 1.38 & 0.97 & 0.82 & 0.97 & 2.48 & 7.44 & 9.06 & 1.68 & 1.30 & 1.37 & 0.84 & 0.74 & $0.90^{* *}$ & 0.94 & 1.05 & 1.09 \\
\hline KRR-ARDI & 0.87 & 0.88 & 0.93 & 0.82 & 0.86 & 0.85 & $1.51^{* *}$ & 3.19 & 4.10 & 1.25 & 1.14 & 1.19 & 0.67 & 0.61 & 0.86 & $0.96^{* *}$ & 0.85 & 0.84 \\
\hline Boosting+MARX & 0.99 & 1.14 & 1.28 & 0.77 & 0.74 & 0.76 & 0.85 & 0.74 & 0.83 & $1.02^{*}$ & 1.03 & 1.15 & 0.66 & 0.61 & 0.85 & $1.00^{* *}$ & 1.00 & 0.99 \\
\hline ARRF,2Ylag & 0.96 & 1.05 & 0.99 & 0.85 & 0.81 & 0.83 & 0.40 & 1.26 & 0.72 & 0.93 & 0.92 & 0.94 & 0.73 & 1.40 & 5.87 & 0.94 & 0.98 & 1.03 \\
\hline FA-ARRF,2Fac & 0.97 & $1.42^{*}$ & 1.95 & 0.89 & 1.17 & 2.52 & 5.91 & 59.67 & 65.78 & 1.15 & 1.27 & 1.58 & 0.90 & 0.71 & 2.84 & 1.03 & 2.82 & 3.12 \\
\hline ARRF,6Ylag & 0.92 & 0.96 & 0.89 & 0.87 & 0.87 & 0.84 & 0.30 & 0.53 & 0.99 & 0.90 & 0.88 & $0.98^{*}$ & 0.92 & 0.69 & 3.79 & 0.94 & 0.93 & 0.96 \\
\hline FA-ARRF,4Fac & 1.00 & $1.41^{*}$ & 1.89 & 0.82 & 1.77 & 2.38 & 2.90 & 16.29 & 29.22 & 1.25 & 1.14 & 1.07 & 0.67 & 0.63 & 0.77 & 1.03 & 3.39 & 5.59 \\
\hline NN-ARDI & 1.11 & 0.87 & 1.26 & 0.92 & 1.05 & 1.21 & 1.31 & 8.10 & 11.57 & 1.03 & 1.16 & 1.28 & $0.64^{*}$ & 0.60 & 0.82 & $1.23^{* * *}$ & 1.03 & 1.11 \\
\hline NN-ARDI+MARX & 1.14 & 1.37 & 1.12 & 1.07 & 1.23 & 2.42 & 4.72 & 16.68 & 21.54 & 2.35 & 1.87 & 2.02 & 0.73 & 1.04 & 0.88 & $1.35^{* *}$ & 1.32 & 2.99 \\
\hline
\end{tabular}

Notes: See Table 4. 
Table 8: Covid Sample (from 2020m1)

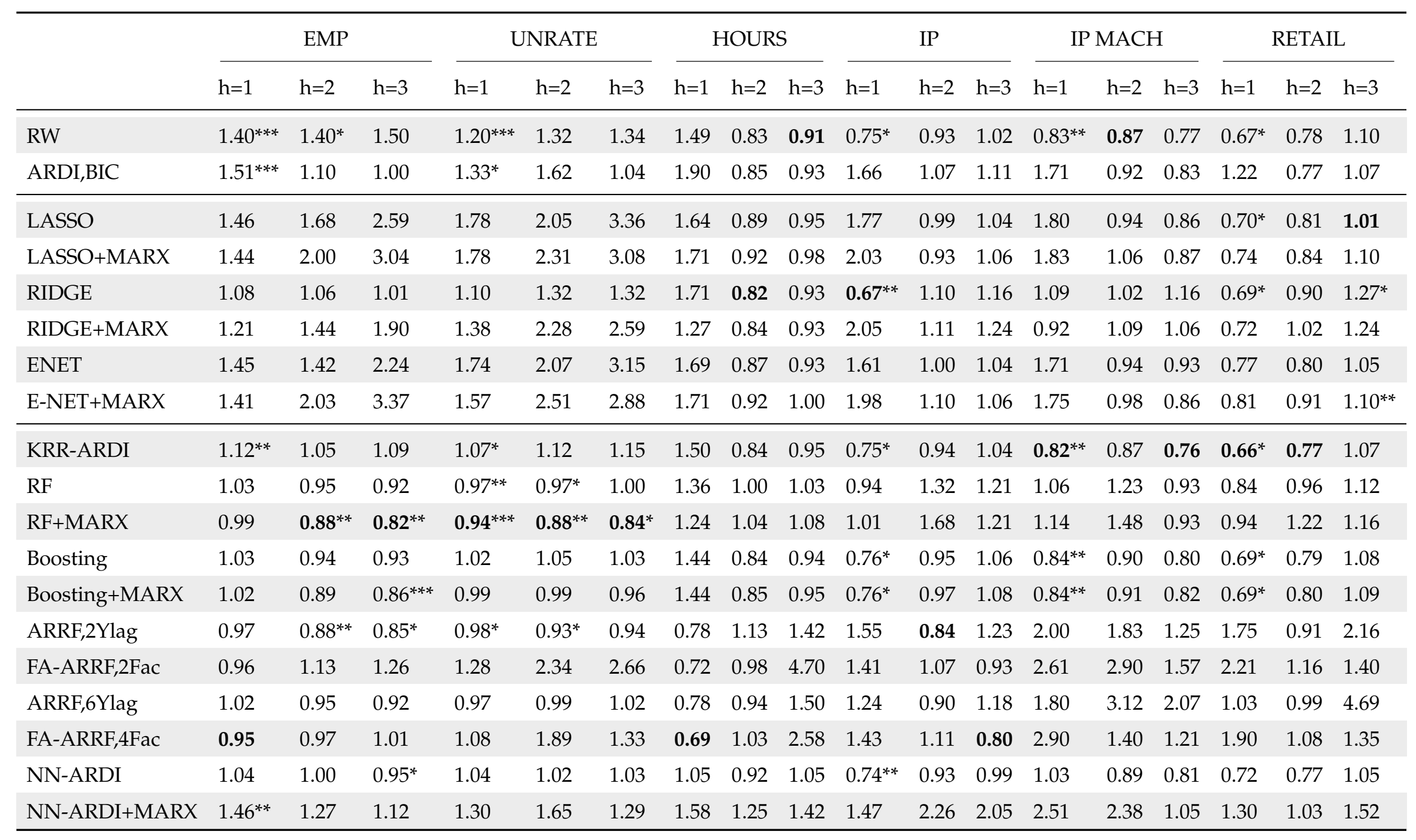

Notes: See Table 4. 
Table 9: Covid Sample (from 2020m1), Continued

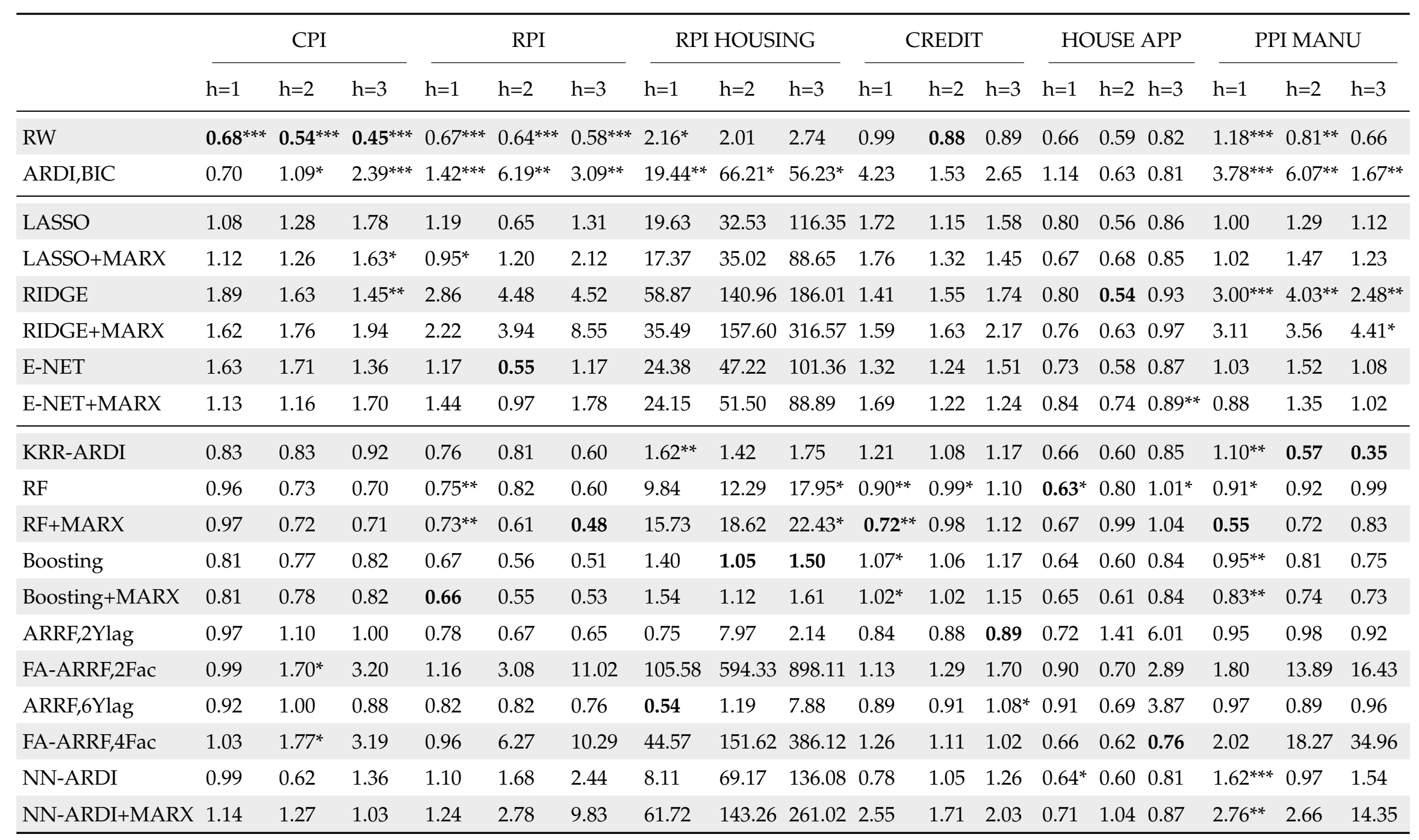

Notes: See Table 4. 
Table 10: Quiet(er) Period (2011-2019)

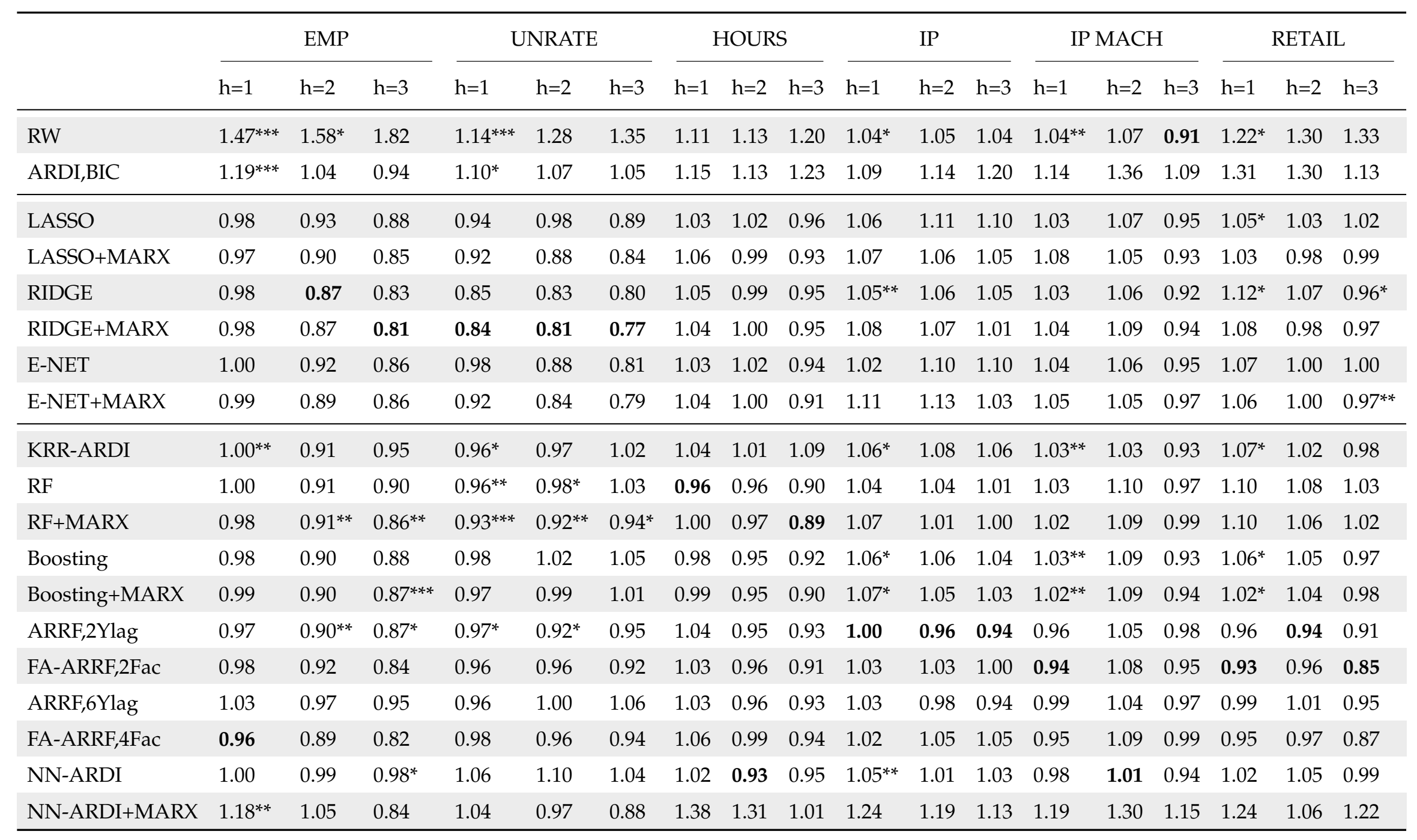

Notes: See Table 4. 
Table 11: Quiet(er) Period (2011-2019), Continued

\begin{tabular}{|c|c|c|c|c|c|c|c|c|c|c|c|c|c|c|c|c|c|c|}
\hline & \multicolumn{3}{|c|}{ CPI } & \multicolumn{3}{|c|}{ RPI } & \multicolumn{3}{|c|}{ RPI HOUSING } & \multicolumn{3}{|c|}{ CREDIT } & \multicolumn{3}{|c|}{ HOUSE APP } & \multicolumn{3}{|c|}{ PPI MANU } \\
\hline & $\mathrm{h}=1$ & $h=2$ & $h=3$ & $\mathrm{~h}=1$ & $h=2$ & $h=3$ & $\mathrm{~h}=1$ & $h=2$ & $h=3$ & $\mathrm{~h}=1$ & $\mathrm{~h}=2$ & $h=3$ & $\mathrm{~h}=1$ & $\mathrm{~h}=2$ & $h=3$ & $\mathrm{~h}=1$ & $\mathrm{~h}=2$ & $h=3$ \\
\hline ARDI,BIC & 1.66 & $1.83^{*}$ & $1.79^{* * *}$ & $1.22^{* * *}$ & $1.42^{* *}$ & $1.50^{* *}$ & $2.42^{* *}$ & $5.50^{*}$ & $6.65^{*}$ & 1.52 & 1.53 & 1.58 & 1.17 & 1.36 & 1.41 & $1.49^{* * *}$ & $1.29^{* *}$ & $1.29^{* *}$ \\
\hline LASSO & 1.28 & 1.19 & 1.28 & 0.79 & 0.79 & 0.79 & 1.46 & 2.51 & 3.06 & 1.74 & 1.56 & 1.62 & 0.92 & 1.01 & 1.09 & 0.90 & 1.01 & 1.08 \\
\hline RIDGE & 1.21 & 1.29 & $1.32^{* *}$ & 0.78 & 0.81 & 0.86 & 1.53 & 2.89 & 3.33 & 1.50 & 1.48 & 1.62 & 1.03 & 1.05 & 1.13 & $1.13^{* * *}$ & $1.06^{* *}$ & $1.08^{* *}$ \\
\hline RIDGE+MARX & 1.09 & 1.13 & 1.14 & 0.75 & 0.74 & 0.81 & 1.35 & 2.99 & 3.52 & 1.61 & 1.59 & 1.58 & 1.08 & 1.14 & 1.19 & 1.04 & 1.04 & $1.07^{*}$ \\
\hline E-NET & 1.26 & 1.13 & 1.11 & 0.80 & 0.78 & 0.81 & 1.36 & 2.37 & 3.11 & 1.79 & 1.53 & 1.69 & 0.91 & 1.01 & 1.13 & 0.92 & 0.98 & 1.10 \\
\hline E-NET+MARX & 1.24 & 1.19 & 1.13 & 0.78 & 0.78 & 0.80 & 1.32 & 2.60 & 2.87 & 1.66 & 1.49 & 1.69 & 0.91 & 1.04 & $1.10^{* *}$ & 0.95 & 1.00 & 1.10 \\
\hline KRR-ARDI & 1.00 & 0.94 & 0.93 & 0.84 & 0.87 & 0.90 & $1.51^{* *}$ & 3.38 & 4.28 & 1.30 & 1.29 & 1.25 & 1.13 & 1.29 & 1.26 & $0.94^{* *}$ & 0.90 & 0.92 \\
\hline Boosting+MARX & 1.46 & 1.65 & 1.62 & 0.82 & 0.79 & 0.81 & 0.81 & 0.70 & 0.77 & $1.02^{*}$ & 1.05 & 1.14 & 0.92 & 0.98 & 1.00 & $1.03^{* *}$ & 1.04 & 1.03 \\
\hline ARRF,2Ylag & 0.93 & 0.98 & 0.98 & 0.87 & 0.84 & 0.87 & 0.38 & 0.52 & 0.61 & 1.07 & 1.00 & 1.07 & 0.97 & 0.95 & 0.96 & 0.94 & 0.98 & 1.05 \\
\hline FA-ARRF,2Fac & 0.91 & $1.04^{*}$ & 1.00 & 0.79 & 0.72 & 0.74 & 0.57 & 1.03 & 1.22 & 1.20 & 1.21 & 1.26 & 1.06 & 1.12 & 1.17 & 0.91 & 0.97 & 1.03 \\
\hline ARRF,6Ylag & 0.91 & 0.91 & 0.90 & 0.89 & 0.88 & 0.86 & 0.29 & 0.46 & 0.46 & 0.93 & 0.81 & $0.74^{*}$ & 0.99 & 0.97 & 0.95 & 0.93 & 0.94 & 0.96 \\
\hline FA-ARRF,4Fac & 0.91 & $0.92^{*}$ & 0.90 & 0.76 & 0.70 & 0.72 & 0.66 & 1.45 & 1.54 & 1.24 & 1.22 & 1.20 & 1.12 & 1.14 & 1.13 & 0.88 & 0.91 & 0.97 \\
\hline NN-ARDI & 1.40 & 1.22 & 1.18 & 0.85 & 0.89 & 0.95 & 0.95 & 1.40 & 1.91 & 1.44 & 1.47 & 1.33 & $0.96^{*}$ & 1.05 & 0.94 & $1.17^{* * *}$ & 1.05 & 1.04 \\
\hline NN-ARDI+MARX & 1.15 & 1.51 & 1.18 & 1.00 & 0.86 & 0.86 & 1.66 & 2.80 & 2.97 & 2.02 & 2.33 & 2.02 & 1.30 & 1.28 & 1.31 & $1.14^{* *}$ & 1.09 & 1.21 \\
\hline
\end{tabular}

Notes: See Table 4. 
Table 12: Pre-Covid (2008-2019)

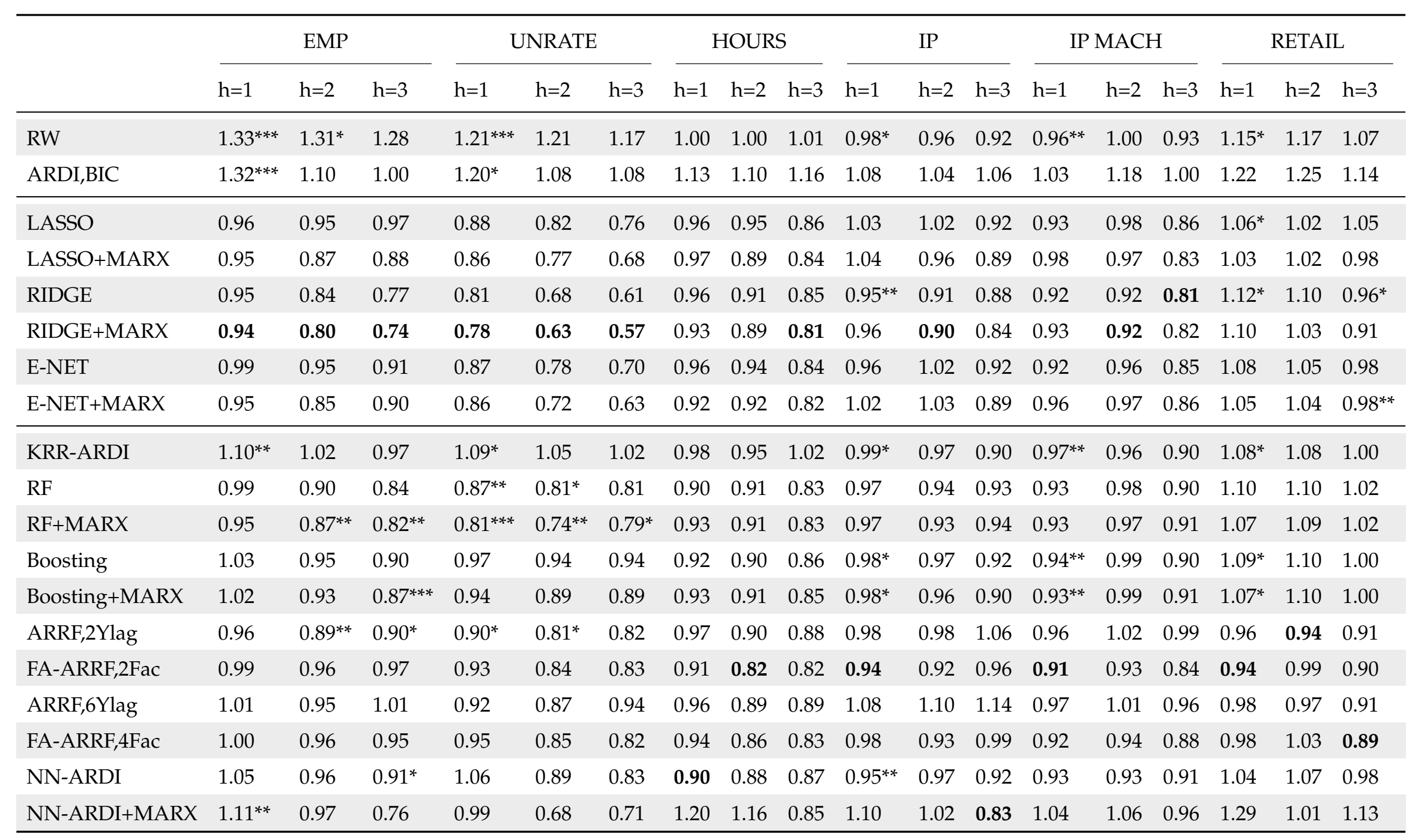

Notes: See Table 4. 
Table 13: Pre-Covid (2008-2019), Continued

\begin{tabular}{|c|c|c|c|c|c|c|c|c|c|c|c|c|c|c|c|c|c|c|}
\hline & $\mathrm{h}=1$ & $\mathrm{~h}=2$ & $h=3$ & $\mathrm{~h}=1$ & $h=2$ & $h=3$ & $\mathrm{~h}=1$ & $\mathrm{~h}=2$ & $h=3$ & $\mathrm{~h}=1$ & $\mathrm{~h}=2$ & $h=3$ & $\mathrm{~h}=1$ & $\mathrm{~h}=2$ & $h=3$ & $\mathrm{~h}=1$ & $\mathrm{~h}=2$ & $h=3$ \\
\hline ARDI,BIC & 1.78 & $1.82^{*}$ & $1.85^{* * *}$ & $1.91^{* * *}$ & $1.93^{* *}$ & $1.66^{* *}$ & $2.66^{* *}$ & $2.86^{*}$ & $2.91^{*}$ & 1.02 & 1.00 & 1.02 & 1.35 & 1.70 & 1.67 & $2.58^{* * *}$ & $1.87^{* *}$ & $1.55^{* *}$ \\
\hline LASSO & 1.08 & 1.05 & 1.22 & 0.69 & 0.97 & 1.09 & 0.33 & 0.63 & 0.83 & 0.93 & 0.77 & 0.74 & 1.12 & 0.96 & 0.95 & 0.96 & 1.12 & 1.17 \\
\hline RIDGE & 1.00 & 1.08 & $1.30^{* *}$ & 0.88 & 1.05 & 1.20 & 0.79 & 0.93 & 0.94 & 0.86 & 0.76 & 0.76 & 0.99 & 0.93 & 0.91 & $1.23^{* * *}$ & $1.24^{* *}$ & $1.32^{* *}$ \\
\hline RIDGE+MARX & 0.97 & 1.01 & 1.15 & 0.77 & 1.02 & 1.11 & 0.60 & 0.88 & 0.86 & 0.94 & 0.86 & 0.87 & 0.99 & 0.86 & 0.86 & 1.11 & 1.12 & $1.27^{*}$ \\
\hline E-NET & 1.02 & 1.03 & 1.16 & 0.83 & 0.95 & 1.09 & 0.35 & 0.64 & 0.85 & 0.95 & 0.76 & 0.77 & 1.02 & 0.93 & 0.92 & 0.95 & 1.17 & 1.27 \\
\hline E-NET+MARX & 1.08 & 1.08 & 1.09 & 0.79 & 0.98 & 1.08 & 0.36 & 0.68 & 0.82 & 0.99 & 0.78 & 0.78 & 1.05 & 0.91 & $0.92^{* *}$ & 1.01 & 1.10 & 1.27 \\
\hline KRR-ARDI & 0.91 & 0.87 & 0.97 & 1.03 & 1.03 & 1.08 & $1.50^{* *}$ & 1.66 & 1.62 & 0.91 & 0.90 & 0.93 & 1.11 & 1.19 & 1.21 & $1.29^{* *}$ & 1.20 & 1.15 \\
\hline Boosting+MARX & 1.05 & 1.09 & 1.20 & 1.01 & 1.03 & 1.08 & 1.13 & 1.27 & 1.27 & $0.81^{*}$ & 0.77 & 0.82 & 1.05 & 1.05 & 1.08 & $1.27^{* *}$ & 1.24 & 1.20 \\
\hline ARRF,2Ylag & 1.85 & 1.14 & 0.97 & 1.02 & 1.04 & 1.20 & 1.20 & 0.96 & 1.08 & 0.97 & 0.97 & 1.02 & 1.02 & 0.98 & 1.13 & 1.00 & 1.08 & 1.36 \\
\hline FA-ARRF,2Fac & 1.54 & $1.19^{*}$ & 1.30 & 0.77 & 0.92 & 1.09 & 0.84 & 0.94 & 0.84 & 0.98 & 0.96 & 1.03 & 1.14 & 0.96 & 1.25 & 1.08 & 1.18 & 1.60 \\
\hline ARRF,6Ylag & 1.60 & 1.25 & 1.22 & 1.05 & 1.22 & 1.33 & 1.22 & 0.97 & 1.56 & 1.17 & 1.12 & $1.27^{*}$ & 1.03 & 1.20 & 1.54 & 1.12 & 1.22 & 1.63 \\
\hline FA-ARRF,4Fac & 1.59 & $1.28^{*}$ & 1.43 & 0.70 & 0.95 & 1.10 & 0.88 & 1.02 & 1.05 & 1.02 & 0.96 & 0.98 & 1.13 & 1.04 & 1.09 & 1.04 & 1.19 & 1.55 \\
\hline NN-ARDI & 1.05 & 1.01 & 1.14 & 1.04 & 1.02 & 1.12 & 0.88 & 1.07 & 1.04 & 0.90 & 0.90 & 0.84 & $1.02^{*}$ & 1.04 & 1.06 & $1.34^{* * *}$ & 1.20 & 1.20 \\
\hline NN-ARDI+MARX & 1.11 & 1.04 & 1.10 & 0.85 & 1.09 & 1.18 & 0.67 & 0.68 & 0.94 & 1.07 & 1.10 & 1.08 & 1.20 & 0.88 & 0.78 & $1.29^{* *}$ & 1.13 & 1.40 \\
\hline
\end{tabular}

Notes: See Table 4. 


\section{B Additional Graphs}

Figure 7: Variable Importance Measures for FA-ARRF(2,2) - HOURS at $h=1$
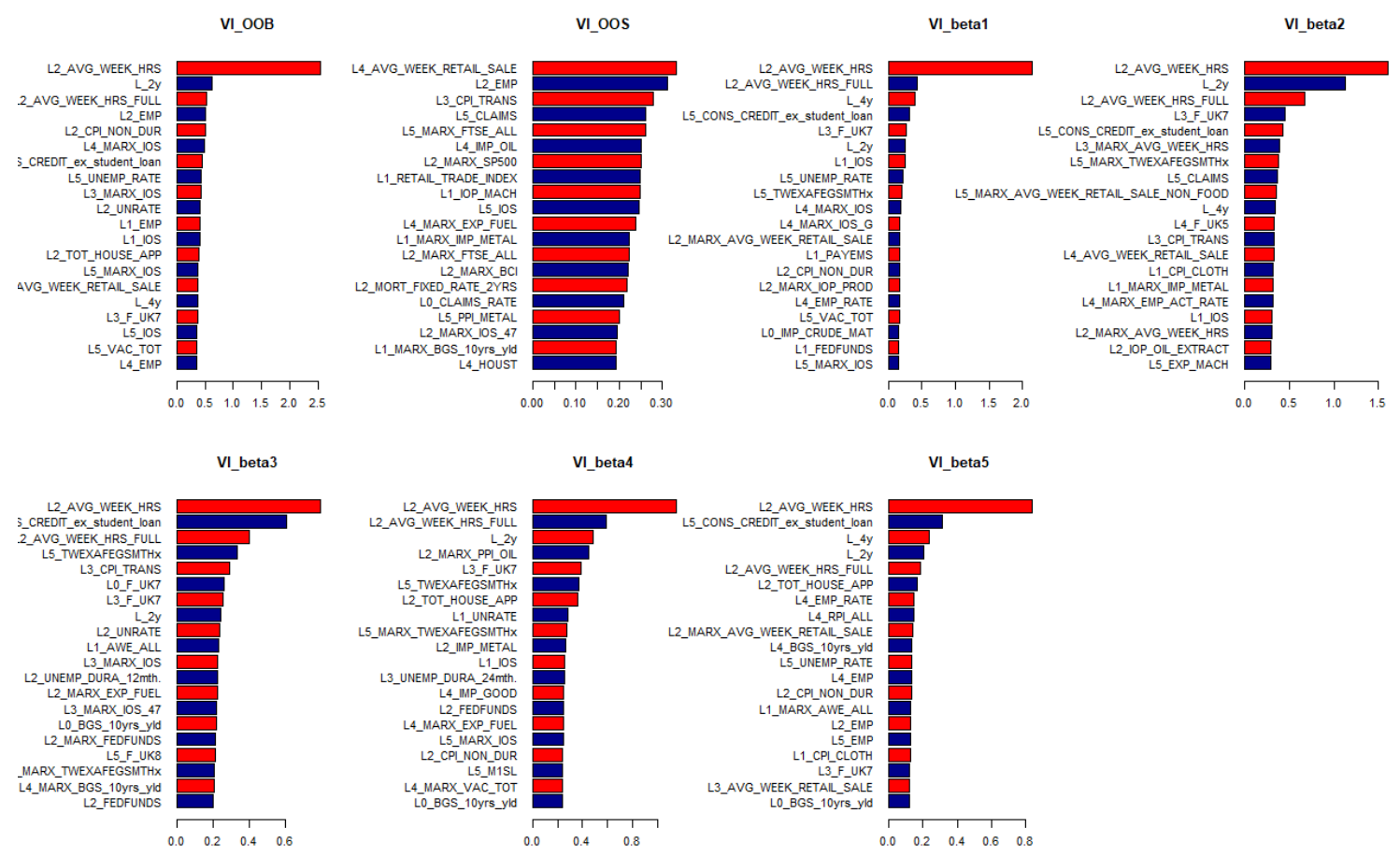

Notes: 20 most important series according to the various variable importance (VI) criteria. Units are relative RMSE gains (in percentage) from including the specific predictor in the forest part. $V I_{O O B}$ means $\mathrm{VI}$ for the out-of-bag criterion. $V I_{O O S}$ is using the hold-out sample. $V I_{\beta}$ is an out-of-bag measure of how much $\beta_{t, k}$ varies by withdrawing a certain predictor. 
Figure 8: Variable Importance Measures for ARRF(6) - RPI HOUSE at $h=1$
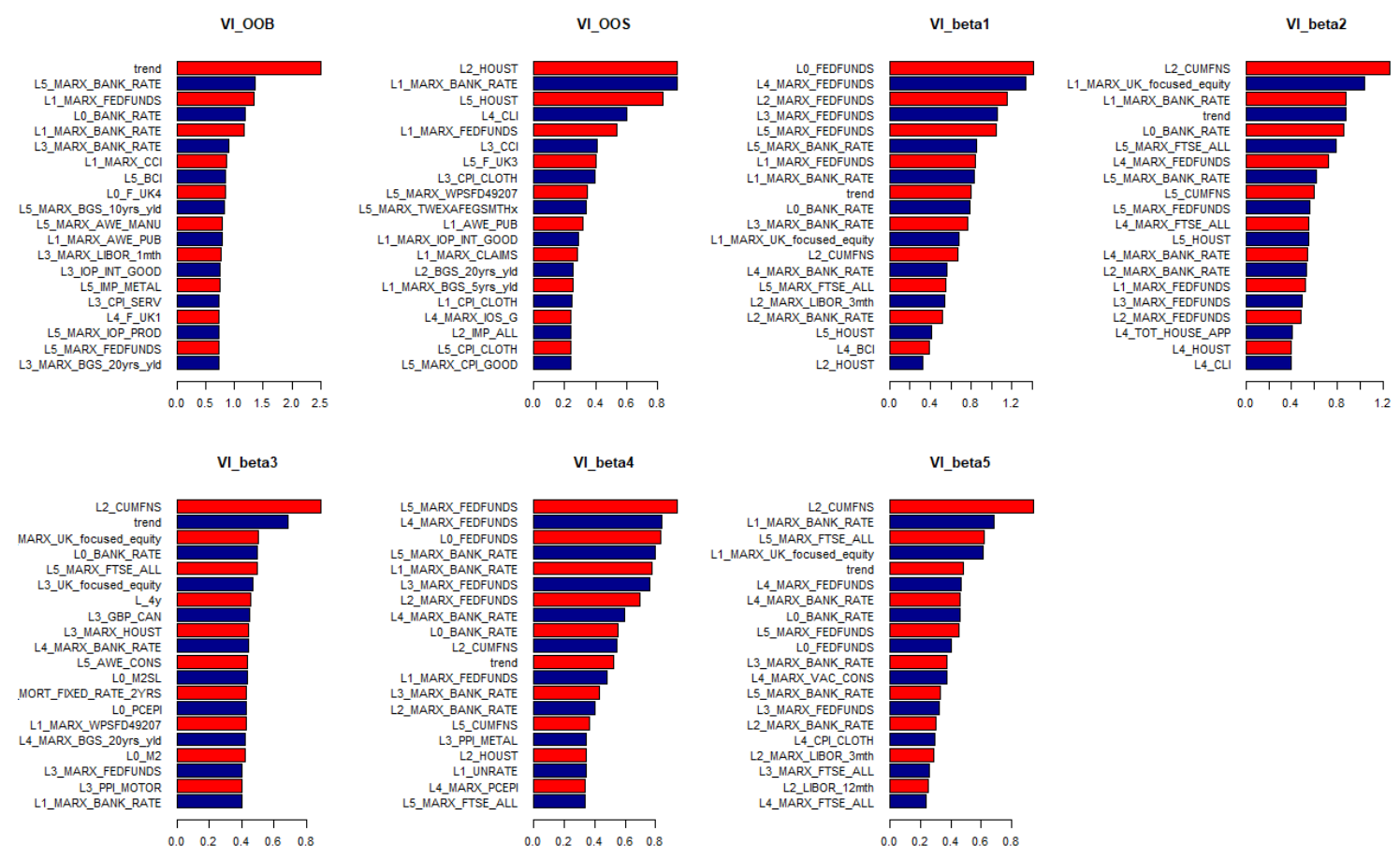

Notes: 20 most important series according to the various variable importance (VI) criteria. Units are relative RMSE gains (in percentage) from including the specific predictor in the forest part. $V I_{O O B}$ means $\mathrm{VI}$ for the out-of-bag criterion. $V I_{O O S}$ is using the hold-out sample. $V I_{\beta}$ is an out-of-bag measure of how much $\beta_{t, k}$ varies by withdrawing a certain predictor.

Figure 9: Full POOS forecasts for RPI HOUSING at $h=1$

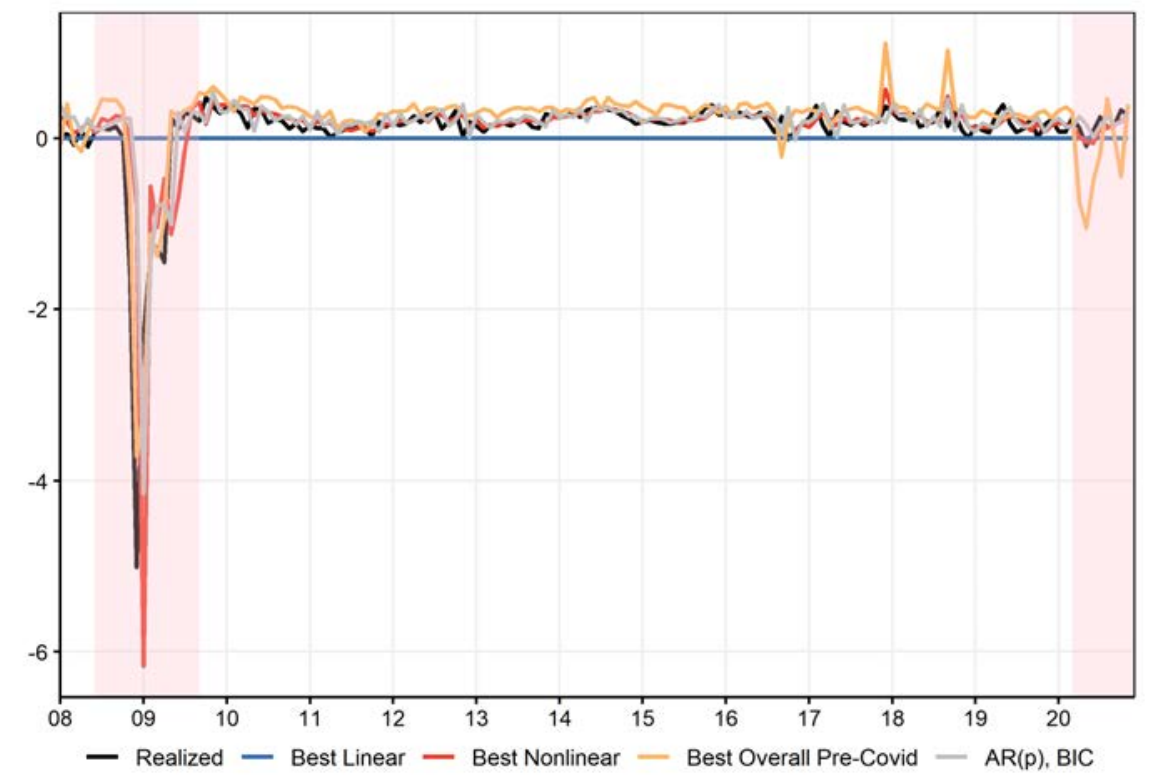

Notes: Pink shading corresponds to recessions. Exact selected models are reported in Table 3. 


\section{UK Large Macroeconomic Dataset}

When available, the series have been retrieved adjusted for seasonality beforehand. However, the price indices (CPI, RPI and PPI) were not and after conducting the Kruskal and Wallis (1952) test for seasonal behavior, these have been seasonally adjusted using the X-13-ARIMA-SEATS software developed by the United States Census Bureau. The transformation codes are: 1 - no transformation; 2 - first difference; 4 - logarithm; 5 - first difference of logarithm.

\begin{tabular}{|c|c|c|c|}
\hline Id. & Start date & End date & Variable \\
\hline 1 & $71-02-01$ & 20-09-01 & EMP \\
\hline 2 & $92-04-01$ & 20-09-01 & EMP_PART \\
\hline 3 & 92-04-01 & 20-09-01 & EMP_TEMP \\
\hline 4 & $71-02-01$ & 20-09-01 & UNEMP_RATE \\
\hline 5 & 92-04-01 & 20-09-01 & UNEMP_DURA_6mth \\
\hline 6 & 92-04-01 & 20-09-01 & UNEMP_DURA_6-12mth \\
\hline 7 & $92-04-01$ & 20-09-01 & UNEMP_DURA_12mth+ \\
\hline 8 & 92-04-01 & 20-09-01 & UNEMP_DURA_24mth+ \\
\hline 9 & $71-02-01$ & 20-09-01 & EMP_RATE \\
\hline 10 & $71-02-01$ & 20-09-01 & EMP_ACT \\
\hline 11 & $71-02-01$ & 20-09-01 & EMP_ACT_RATE \\
\hline 12 & 71-01-01 & 20-11-01 & CLAIMS \\
\hline 13 & 71-01-01 & 20-11-01 & CLAIMS_RATE \\
\hline 14 & 71-02-01 & 20-09-01 & TOT_WEEK_HRS \\
\hline 15 & 92-04-01 & 20-09-01 & AVG_WEEK_HRS \\
\hline 16 & $92-04-01$ & 20-09-01 & AVG_WEEK_HRS_FULL \\
\hline 17 & 00-01-01 & $20-10-01$ & AWE_ALL \\
\hline 18 & 00-01-01 & $20-10-01$ & AWE_CONS \\
\hline 19 & 00-01-01 & $20-10-01$ & AWE_MANU \\
\hline 20 & 00-01-01 & $20-10-01$ & AWE_PRIV \\
\hline 21 & 00-01-01 & $20-10-01$ & AWE_PUB \\
\hline 22 & 00-01-01 & $20-10-01$ & AWE_SERV \\
\hline 23 & $75-02-01$ & $20-10-01$ & VAC_TOT \\
\hline 24 & 01-05-01 & $20-10-01$ & VAC_CONS \\
\hline 25 & 01-05-01 & $20-10-01$ & VAC_MANU \\
\hline 26 & 68-01-01 & 20-11-01 & IOP_PROD \\
\hline 27 & $95-01-01$ & 20-11-01 & IOP_CAP_GOOD \\
\hline 28 & 95-01-01 & 20-11-01 & IOP_DUR \\
\hline 29 & $95-01-01$ & 20-11-01 & IOP_ENER \\
\hline 30 & $95-01-01$ & 20-11-01 & IOP_GOOD \\
\hline 31 & 95-01-01 & 20-11-01 & IOP_INT_GOOD \\
\hline 32 & 68-01-01 & $20-11-01$ & IOP_MACH \\
\hline 33 & 68-01-01 & 20-11-01 & IOP_MANU \\
\hline 34 & 68-01-01 & $20-11-01$ & IOP_MINE \\
\hline 35 & $95-01-01$ & $20-11-01$ & IOP_NON_DUR \\
\hline 36 & 68-01-01 & 20-11-01 & IOP_PETRO \\
\hline 37 & 95-01-01 & 20-11-01 & IOP_OIL_EXTRACT \\
\hline 38 & $97-01-01$ & 20-11-01 & IOS \\
\hline 39 & $97-01-01$ & 20-11-01 & IOS_45 \\
\hline 40 & 97-01-01 & 20-11-01 & IOS_46 \\
\hline 41 & $97-01-01$ & 20-11-01 & IOS_47 \\
\hline 42 & $97-01-01$ & $20-11-01$ & IOS_G \\
\hline 43 & 97-01-01 & 20-11-01 & IOS_EDUC \\
\hline 44 & $97-01-01$ & 20-11-01 & IOS_PNDS \\
\hline 45 & $96-01-01$ & 20-11-01 & RSI \\
\hline 46 & 60-01-01 & $20-11-01$ & CAR_REGIS \\
\hline 47 & 60-01-01 & $20-10-01$ & RETAIL_TRADE_INDEX \\
\hline 48 & $96-01-01$ & 20-11-01 & AVGW_RET_SALE \\
\hline 49 & 94-01-01 & 20-11-01 & AVGW_RET_SALE_NF \\
\hline 50 & 88-01-01 & 20-11-01 & CPIH_ALL \\
\hline 51 & 88-01-01 & 20-11-01 & CPI_ALL \\
\hline 52 & 88-01-01 & 20-11-01 & CPI_EX_ENER \\
\hline 53 & 88-01-01 & 20-11-01 & CPI_GOOD \\
\hline 54 & 88-01-01 & 20-11-01 & CPI_DUR \\
\hline 55 & 88-01-01 & 20-11-01 & CPI_NON_DUR \\
\hline 56 & 88-01-01 & 20-11-01 & CPI_SERV \\
\hline 57 & 88-01-01 & 20-11-01 & CPI_CLOTH \\
\hline 58 & 88-01-01 & 20-11-01 & CPI_TRANS \\
\hline 59 & 87-01-01 & 20-11-01 & RPI_ALL \\
\hline 60 & 87-01-01 & 20-11-01 & RPI_GOOD \\
\hline 61 & 87-01-01 & 20-11-01 & RPI_SERV \\
\hline 62 & 87-01-01 & 20-11-01 & RPI_HOUSE \\
\hline
\end{tabular}

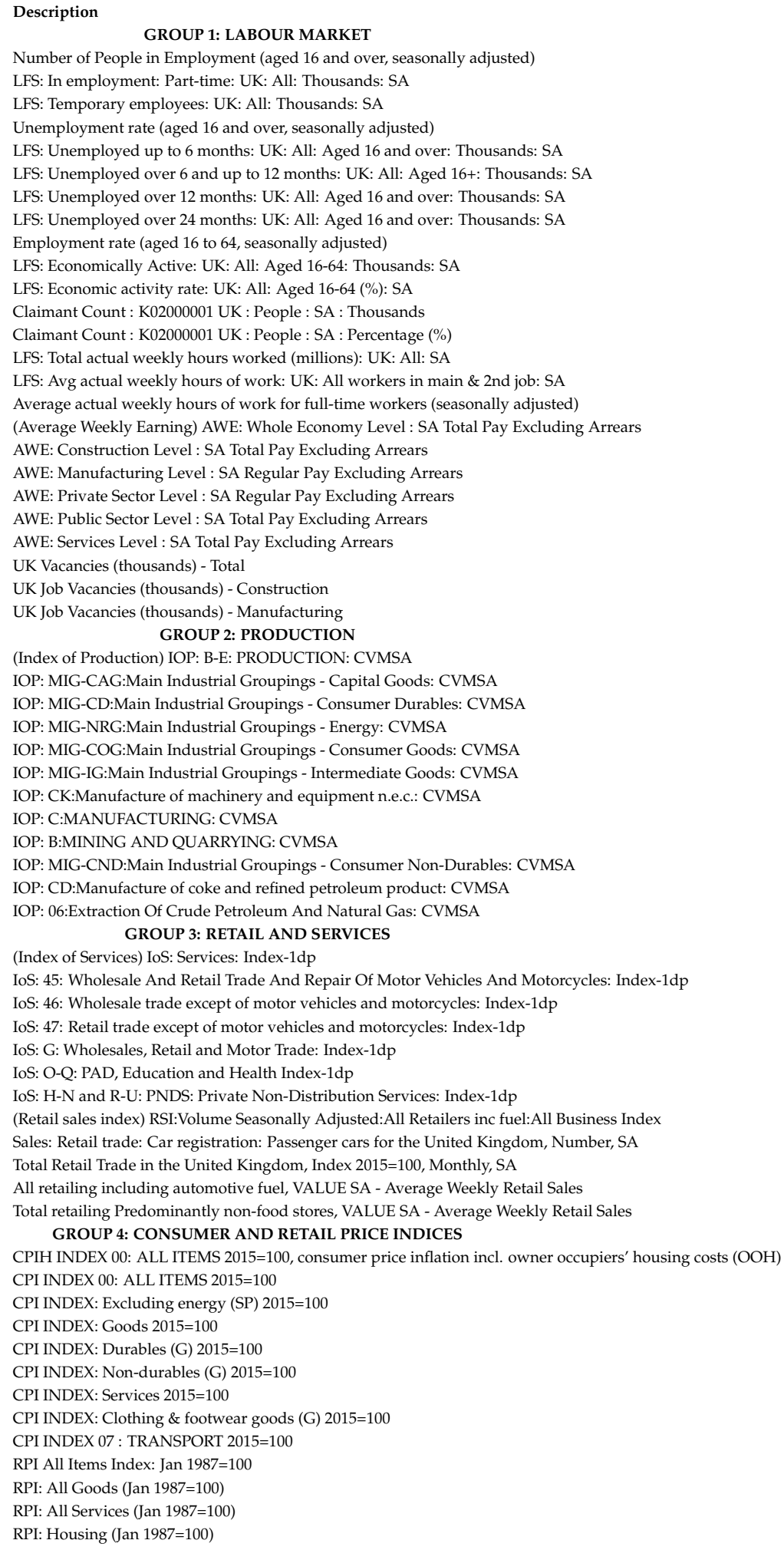

\begin{tabular}{|c|c|}
\hline Source & C \\
\hline ONS & 5 \\
\hline ONS & 5 \\
\hline ONS & 5 \\
\hline ONS & 2 \\
\hline ONS & 5 \\
\hline ONS & 5 \\
\hline ONS & 5 \\
\hline ONS & 5 \\
\hline ONS & 2 \\
\hline ONS & 5 \\
\hline ONS & 2 \\
\hline ONS & 5 \\
\hline ONS & 2 \\
\hline ONS & 5 \\
\hline ONS & 5 \\
\hline ONS & 5 \\
\hline ONS & 5 \\
\hline ONS & 5 \\
\hline ONS & 5 \\
\hline ONS & 5 \\
\hline ONS & 5 \\
\hline ONS & 5 \\
\hline FRED/ONS & 5 \\
\hline ONS & 5 \\
\hline ONS & 5 \\
\hline ONS & 5 \\
\hline ONS & 5 \\
\hline ONS & 5 \\
\hline ONS & 5 \\
\hline ONS & 5 \\
\hline ONS & 5 \\
\hline ONS & 5 \\
\hline ONS & 5 \\
\hline ONS & 5 \\
\hline ONS & 5 \\
\hline ONS & 5 \\
\hline ONS & 5 \\
\hline ONS & 5 \\
\hline ONS & 5 \\
\hline ONS & 5 \\
\hline ONS & 5 \\
\hline ONS & 5 \\
\hline ONS & 5 \\
\hline ONS & 5 \\
\hline ONS & 5 \\
\hline FRED & 5 \\
\hline FRED & 5 \\
\hline ONS & 5 \\
\hline ONS & 5 \\
\hline ONS & 5 \\
\hline ONS & 5 \\
\hline ONS & 5 \\
\hline ONS & 5 \\
\hline ONS & 5 \\
\hline ONS & 5 \\
\hline ONS & 5 \\
\hline ONS & 5 \\
\hline ONS & 5 \\
\hline ONS & 5 \\
\hline ONS & 5 \\
\hline ONS & 5 \\
\hline ONS & 5 \\
\hline
\end{tabular}




\begin{tabular}{|c|c|c|c|c|c|c|}
\hline 63 & 97-01-01 & 20-11-01 & EXP_TOT & Total Trade (TT): WW: Exports: BOP: CVM: SA & ONS & 5 \\
\hline 64 & $97-01-01$ & 20-11-01 & EXP_GOOD & Trade in Goods (T): WW: Exports: BOP: CVM: SA & ONS & 5 \\
\hline 65 & 97-01-01 & 20-11-01 & IMP_ALL & Total Trade (TT): WW: Imports: BOP: CVM: SA & ONS & 5 \\
\hline 66 & 97-01-01 & 20-11-01 & IMP_GOOD & Trade in Goods (T): WW: Imports: BOP: CVM: SA & ONS & 5 \\
\hline 67 & 97-01-01 & 20-11-01 & EXP_FUEL & Trade in Goods: Fuels (3): WW: Exports: BOP: CVM: SA & ONS & 5 \\
\hline 68 & 97-01-01 & 20-11-01 & IMP_FUEL & Trade in Goods: Fuels (3): WW: Imports: BOP: CVM: SA & ONS & 5 \\
\hline 69 & 97-01-01 & 20-11-01 & EXP_OIL & Trade in Goods: Crude oil (33O): WW: Exports: BOP: CVM: SA & ONS & 5 \\
\hline 70 & 97-01-01 & 20-11-01 & IMP_OIL & Trade in Goods: Crude oil (33O): WW: Imports: BOP: CVM: SA & ONS & 5 \\
\hline 71 & $97-01-01$ & 20-11-01 & EXP_MACH & Trade in Goods: Machinery and Transport (7): WW: Exports: BOP: CVM: SA & ONS & 5 \\
\hline 72 & 97-01-01 & 20-11-01 & IMP_MACH & Trade in Goods: Machinery and Transport (7): WW: Imports: BOP: CVM: SA & ONS & 5 \\
\hline 73 & $97-01-01$ & 20-11-01 & EXP_METAL & Trade in Goods: Metal ores \& scrap (28): WW: Exports: BOP: CVM: SA & ONS & 5 \\
\hline 74 & 97-01-01 & 20-11-01 & IMP_METAL & Trade in Goods: Metal ores \& scrap (28): WW: Imports: BOP: CVM: SA & ONS & 5 \\
\hline 75 & 97-01-01 & 20-11-01 & EXP_CRUDE_MAT & Trade in Goods: Crude Materials (2): WW: Exports: BOP: CVM: SA & ONS & 5 \\
\hline 76 & 97-01-01 & 20-11-01 & IMP_CRUDE_MAT & Trade in Goods: Crude Materials (2): WW: Imports: BOP: CVM: SA & ONS & 5 \\
\hline 77 & 80-01-01 & 20-12-01 & GBP_BROAD & Monthly average Broad Effective exchange rate index, Sterling (Jan $2005=100$ ) XUMABK82 & $\mathrm{BOE}$ & 5 \\
\hline 78 & 75-01-01 & 20-12-01 & GBP_CAN & Monthly average Spot exchange rate, Canadian Dollar into Sterling XUMACDS & BOE & 5 \\
\hline 79 & 99-01-01 & 20-12-01 & GBP_EUR & Monthly average Spot exchange rate, Euro into Sterling XUMAERS & $\mathrm{BOE}$ & 5 \\
\hline 80 & 75-01-01 & 20-12-01 & GBP_JAP & Monthly average Spot exchange rate, Japanese Yen into Sterling XUMAJYS & BOE & 5 \\
\hline 81 & 75-01-01 & 20-12-01 & GBP_US & Monthly average Spot exchange rate, US\$ into Sterling XUMAUSS & $\mathrm{BOE}$ & 5 \\
\hline \multirow[t]{2}{*}{82} & 87-06-01 & 20-12-01 & OIL_PRICE & Crude Oil Prices: Brent - Europe, Dollars per Barrel, Monthly, NSA & BOE & 5 \\
\hline & & & & GROUP 6: MONEY, CREDIT AND INTEREST RATES & & \\
\hline 83 & 75-01-01 & 20-12-01 & BANK_RATE & Monthly average of official Bank Rate [a] [b] IUMABEDR & $\mathrm{BOE}$ & 2 \\
\hline \multirow[t]{2}{*}{84} & 93-04-01 & 20-11-01 & CONS_CREDIT & Monthly amounts outstanding of total (excluding the Student Loans Company) sterling consumer credit & & \\
\hline & & & & lending to individuals (in sterling millions) SA & $\mathrm{BOE}$ & 5 \\
\hline 85 & $97-10-01$ & 20-11-01 & TOT_LENDING_APP & Monthly number of total sterling approvals for secured lending to individuals SA & $\mathrm{BOE}$ & 5 \\
\hline 86 & 93-04-01 & 20-11-01 & TOT_HOUSE_APP & Monthly number of total sterling approvals for house purchase to individuals SA & $\mathrm{BOE}$ & 5 \\
\hline \multirow[t]{2}{*}{87} & 95-01-01 & 20-12-01 & MORT_FRATE_5YRS & Monthly interest rate of UK monetary financial institutions (excl. Central Bank) sterling 5 year (75\% LTV) & & \\
\hline & & & & fixed rate mortgage to households (in percent) NSA & $\mathrm{BOE}$ & 2 \\
\hline \multirow[t]{2}{*}{88} & 95-01-01 & 20-12-01 & MORT_FRATE_2YRS & Monthly interest rate of UK monetary financial institutions (excl. Central Bank) sterling 2 year (75\% LTV) & & \\
\hline & & & & fixed rate mortgage to households (in percent) NSA & BOE & 2 \\
\hline \multirow[t]{2}{*}{89} & 86-09-01 & 20-11-01 & M1 & Monthly amounts outstanding of monetary financial institutions' sterling and all foreign currency M1 & & \\
\hline & & & & (UK estimate of EMU aggregate) liabilities to private and public sectors (in sterling millions) SA & $\mathrm{BOE}$ & 5 \\
\hline \multirow[t]{2}{*}{90} & $86-12-01$ & 20-11-01 & M2 & Monthly amounts outstanding of monetary financial institutions' sterling and all foreign currency M2 & & \\
\hline & & & & (UK estimate of EMU aggregate) liabilities to private and public sectors (in sterling millions) SA & $\mathrm{BOE}$ & 5 \\
\hline \multirow[t]{2}{*}{91} & 87-01-01 & 20-11-01 & M3 & Monthly amounts outstanding of monetary financial institutions' sterling and all foreign currency M3 & & \\
\hline & & & & (UK estimate of EMU aggregate) liabilities to private and public sectors (in sterling millions) SA & BOE & 5 \\
\hline \multirow[t]{2}{*}{92} & 82-06-01 & 20-09-01 & M4 & Monthly amounts outstanding of M4 (monetary financial institutions' sterling M4 liabilities to private sector) & & \\
\hline & & & & (in sterling millions) SA & BOE & 5 \\
\hline 93 & 86-01-01 & 20-12-01 & LIBOR_1mth & 1-Month London Interbank Offered Rate (LIBOR), based on British Pound, Percent, Monthly, NSA & FRED & 2 \\
\hline 94 & 86-01-01 & 20-12-01 & LIBOR_3mth & 3-Month London Interbank Offered Rate (LIBOR), based on British Pound, Percent, Monthly, NSA & FRED & 2 \\
\hline 95 & 86-01-01 & 20-12-01 & LIBOR_12mth & 12-Month London Interbank Offered Rate (LIBOR), based on British Pound, Percent, Monthly, NSA & FRED & 2 \\
\hline 96 & 93-12-01 & 20-12-01 & BGS_5yrs_yld & Monthly average yield from British Government Securities, 5 year Nominal Par Yield & $\mathrm{BOE}$ & 2 \\
\hline 97 & $93-12-01$ & $20-12-01$ & BGS_10yrs_yld & Monthly average yield from British Government Securities, 10 year Nominal Par Yield & BOE & 2 \\
\hline \multirow[t]{2}{*}{98} & 00-01-01 & 20-12-01 & BGS_20yrs_yld & Monthly average yield from British Government Securities, 20 year Nominal Par Yield & $\mathrm{BOE}$ & 2 \\
\hline & & & & GROUP 7: STOCK MARKET & & \\
\hline 99 & $80-02-01$ & 20-12-01 & FTSE_ALL & UK FTSE All Share (FTAS) & YAHOO & 5 \\
\hline 100 & $85-12-01$ & 20-12-01 & FTSE250 & FTSE 250 (FTMC) & YAHOO & 5 \\
\hline 101 & 90-01-01 & 20-12-01 & VIX & CBOE Volatility Index (VIX) & YAHOO & 1 \\
\hline 102 & 60-01-01 & 20-12-01 & SP500 & S\&P 500 (GSPC) & YAHOO & 5 \\
\hline 103 & 96-03-01 & 20-12-01 & UK_focused_equity & iShares MSCI United Kingdom ETF (EWU) & YAHOO & 5 \\
\hline \multirow[t]{2}{*}{104} & $87-01-01$ & 20-12-01 & EUR_UNC_INDEX & Economic Policy Uncertainty Index for Europe, Index, Monthly, NSA & FRED & 2 \\
\hline & & & & GROUP 8: SENTIMENT AND LEADING INDICATORS & & \\
\hline 105 & 77-03-01 & 20-11-01 & $\mathrm{BCI}$ & Business confidence index (BCI)Amplitude adjusted, Long-term average $=100$ & OECD & 2 \\
\hline 106 & 74-01-01 & 20-12-01 & $\mathrm{CCI}$ & Consumer confidence index (CCI)Amplitude adjusted, Long-term average $=100$ & OECD & 2 \\
\hline \multirow[t]{2}{*}{107} & 60-01-01 & 20-12-01 & CLI & Composite leading indicator (CLI)Amplitude adjusted, Long-term average $=100$ & OECD & 2 \\
\hline & & & & GROUP 9: PRODUCER PRICE INDICES & & \\
\hline 108 & 60-01-01 & 20-11-01 & PPI_MANU & Producer price indices (PPI)Manufacturing, domestic market, 2015=100 & OECD & 5 \\
\hline 109 & 96-01-01 & 20-11-01 & PPI_MACH & PPI Machinery and Equipment N.E.C. for Domestic Market (G6VG) & ONS & 5 \\
\hline 110 & 96-01-01 & 20-11-01 & PPI_OIL & PPI Coke and Refined Petroleum Products for Domestic Market (G6ST) & ONS & 5 \\
\hline 111 & 96-01-01 & 20-11-01 & PPI_METAL & PPI Basic Metals for Domestic Market (G6SZ) & ONS & 5 \\
\hline 112 & 96-01-01 & 20-11-01 & PPI_MOTOR & PPI Motor Vehicles, Trailers and Semi-Trailers for Domestic Market (G6WH) & ONS & 5 \\
\hline
\end{tabular}




\section{US Data}

The additional transformation codes are: 6 - second difference of logs; $7-\delta\left(x_{t} / x_{t-1}-1\right)$.

$\begin{array}{lll}\text { Start date } & \text { End date } & \text { Variable } \\ \text { 98-01-01 } & 20-11-01 & \text { W875RX1 } \\ \text { 98-01-01 } & 20-11-01 & \text { INDPRO } \\ 98-01-01 & 20-11-01 & \text { CUMFNS } \\ \text { 98-01-01 } & 20-11-01 & \text { UNRATE } \\ 98-01-01 & 20-11-01 & \text { PAYEMS } \\ 98-01-01 & 20-11-01 & \text { CES0600000008 } \\ 98-01-01 & 20-11-01 & \text { HOUST } \\ 98-01-01 & 20-11-01 & \text { DPCERA3M086SBEA } \\ \text { 98-01-01 } & 20-11-01 & \text { CMRMTSPLx } \\ \text { 98-01-01 } & 20-11-01 & \text { M1SL } \\ \text { 98-01-01 } & 20-11-01 & \text { M2SL } \\ \text { 98-01-01 } & 20-11-01 & \text { TOTRESNS } \\ \text { 98-01-01 } & 20-11-01 & \text { NONBORRES } \\ \text { 98-01-01 } & 20-11-01 & \text { FEDFUNDS } \\ \text { 98-01-01 } & 20-11-01 & \text { GS10 } \\ \text { 98-01-01 } & 20-11-01 & \text { TWEXAFEGSMTHx } \\ \text { 98-01-01 } & 20-11-01 & \text { WPSFD49207 } \\ \text { 98-01-01 } & 20-11-01 & \text { CPIAUCSL } \\ \text { 98-01-01 } & 20-11-01 & \text { PCEPI }\end{array}$

Description

Real personal income ex transfer receipts

IP Index

Capacity Utilization: Manufacturing

Civilian Unemployment Rate

All Employees: Total nonfarm

Avg Hourly Earnings : Goods-Producing

Housing Starts: Total New Privately Owned

Real personal consumption expenditures

Real Manu. and Trade Industries Sales

M1 Money Stock

M2 Money Stock

Total Reserves of Depository Institutions

Reserves Of Depository Institutions

Effective Federal Funds Rate

10-Year Treasury Rate

Trade Weighted U.S. Dollar Index

PPI: Finished Goods

CPI : All Items

Personal Cons. Expend.: Chain Index

$\begin{array}{lc}\text { Source } & \text { Code } \\ \text { FREDMD } & 5 \\ \text { FREDMD } & 5 \\ \text { FREDMD } & 2 \\ \text { FREDMD } & 2 \\ \text { FREDMD } & 5 \\ \text { FREDMD } & 6 \\ \text { FREDMD } & 4 \\ \text { FREDMD } & 5 \\ \text { FREDMD } & 5 \\ \text { FREDMD } & 6 \\ \text { FREDMD } & 6 \\ \text { FREDMD } & 6 \\ \text { FREDMD } & 7 \\ \text { FREDMD } & 2 \\ \text { FREDMD } & 2 \\ \text { FREDMD } & 5 \\ \text { FREDMD } & 6 \\ \text { FREDMD } & 6 \\ \text { FREDMD } & 6\end{array}$

